\title{
Evolução dos Toxodontia da América do Sul durante o Cenozoico: aspectos dentários, paleoclimáticos e paleoambientais
}

\author{
Evolution of Toxodontia from South America during the Cenozolc: dental, paleoclimatic and paleoenvironmental aspects. \\ Patrícia Rodrigues BraunN ${ }^{1}$ \& Ana Maria Ribeiro $0^{1,2}$ \\ 1- Univ. Fed. do Rio Grande do Sul, Prog. de Pós Grad. em Geociências, Porto Alegre, RS, Brasil. - pbraunn@gmail.com \\ 2- Museu de Ciências Naturais, Fund. Zoobotânica do RS. (MCN/FZBRS), Porto Alegre, RS, Brasil. - ana-ribeiro@fzb.rs.gov.br
}

ABSTRACT: The notoungulates are native South American ungulates recorded from the Paleocene to the Pleistocene, and whose diversity declined dramatically during the Pliocene, reaching Central America and North America during the Pleistocene. Notoungulates evolved under climatic and environmental influence, from archaic lineages, with generalized masticatory apparatus, with complete dentition, without diastema, and with brachydont premolars and molars, to specialized forms with hypertrophied incisors, simplified occlusal crown patterns and protohypsodont and euhypsodont forms. These communities lived first in warm and humid forest habitats, and later, in relatively temperate grasslands in open habitats with a strong tendency towards aridization and cooling, throughout the Cenozoic. Besides the evolution of dental macroscopic morphology observed in Notoungulata, it is also possible to observe the evolution of the types of enamel microstructure, by the presence of more derived characteristics in euhypsodont forms, indicating functional adaptation and providing greater resistance to consumption of more abrasive vegetation.

\section{Introdução}

"A noite da história da vida desses animais chegou antes de podermos admirá-los".

(Cartelle 1994, p. 98, sobre os ungulados nativos sul-americanos)

\section{Mamíferos cenozoicos da América do Su}

A paleomastofauna terrestre da América do Sul (AS) é bastante abundante e de grande importância, devido à sua história de isolamento biogeográfico (e.g. Simpson 1980, Woodburne et al. 2014), tendo estado separada da América do Norte (AN) desde início do Paleoceno até o Plioceno. Estudos tectônicos na região do Caribe indicam que no final do Cretáceo, durante o Campaniano e principalmente no Maastrichtiano, houve uma conexão intermitente entre as Américas através de pontes terrestres, o que é sugerido pela chegada a AS dos primeiros mamíferos térios, além de alguns grupos de dinossauros (Case et al. 2005, Fanti 2012, Goin
Manuscrito:

Recebido:24/08/2016

Corrigido: 25/01/2017

Aceito: 19/07/2017

Citation: Braunn P. R. \& Ribeiro A. M. 2017. Evolução dos Toxodontia da América do Sul durante o Cenozoico: aspectos dentários, paleoclimáticos e paleoambientais. Terræ Didatica, 12(3):127-145. $<$ http://www.ige.unicamp.br/terraedidatica/>.

Keywords: Cenozoic, Paleonvironmental changes, Paleoclimatic changes, Notoungulata, Dental Paleohistology. 
1985, Bonaparte 1990, Rougier et al. 2009a, b, Goin et al. 2012). Excetuando-se provavelmente os multituberculados, os demais grupos originaram-se em faunas do Jurássico superior do Gondwana, sofrendo uma radiação no Cretáceo, no intervalo denominado "Episódio Gondwana" por Pascual e Ortiz-Jaureguizar (2007). Entretanto, Goin et al. (2012) sugerem que a diversificação destes táxons tenha ocorrido no Cretáceo superior (Cenomaniano-Maastrichiano), desencadeada pelo aquecimento global iniciado no Cenomaniano.

No Paleoceno, os primeiros mamíferos tribosfênicos (o protocone do molar superior macera o alimento na superfície em forma de bacia do molar inferior, o talonido), os metatérios e, em seguida, os placentários, foram introduzidos na AS por meio de um evento imigratório provavelmente iniciado no Cretáceo, pelo menos ao que se refere aos metatérios (Case et al. 2005, Woodburne et al. 2014). A grande diversidade de metatérios observada na fauna de Tiumpampa, no Paleoceno (Idades Mamíferos Terrestres Sul-Americanos/SALMA Tiupampense) da Bolívia e as estreitas afinidades filogenéticas de alguns táxons com metatérios da AN corroboram a hipótese de uma origem norte-americana para o grupo. Tal proposição também é reforçada pela presença de Cocatherium, o mais antigo registro de mamífero tério da AS até o momento, do Paleoceno inferior do oeste da Patagônia (Goin et al. 2006, Gelfo et al. 2009). Pelas informações existentes até o presente momento, nenhuma forma de mamífero eutério acompanhou os primeiros metatérios, sendo que os primeiros placentários reportados para o Paleoceno foram "condylarthras" Kolpaniinae e outros grupos de ungulados arcaicos, como os pantodontes (Woodburne et al. 2014).

\section{A origem dos ungulados nativos sul-americanos}

No que concerne à dispersão dos mamíferos eutérios na AS, uma das mais notáveis radiações ocorreu a partir do surgimento dos ungulados nativos sul-americanos durante o Paleoceno, até seu desaparecimento no Pleistoceno superior-Holoceno. Em sua maioria, estes mamíferos caracterizam-se por apresentarem pré-molares e molares lofodontes (dentes nos quais, em sua superfície oclusal, devido ao desgaste, as cúspides unem-se entre si, formando cristas transversais ou lofos) e, membros dotados de cascos. São reconhecidas as ordens Notoungulata, Litopterna, Astrapotheria, Xenungulata e Pyrotheria, além dos "Condylar- thra" Didolodontidae e Kolpaniinae, todas praticamente restritas ao continente sul-americano (Paula Couto 1979, Simpson 1980, Cifelli 1985, Pascual \& Ortiz-Jaureguizar 2007), embora sua presença também seja reportada para o Eoceno da Antártica (Bond et al. 2006, 2011, Gelfo et al. 2009, Reguero et al. 2013) e Pleistoceno da América Central (AC) e AN (Van Frank 1957, Webb \& Perrigo 1984, Lundelius et al. 2013).

No Brasil, dentre os mamíferos fósseis paleógenos e neógenos, os ungulados nativos são bem representados nas bacias de: Itaboraí no Rio de Janeiro (Formação Itaboraí, Eoceno) (Bergqvist \& Ribeiro 1998, Oliveira \& Goin 2011), Curitiba (Formação Guabirotuba, Eoceno-Oligoceno) (Sedor et al. 2017), Taubaté em São Paulo (Formação Tremembé, Oligoceno) (Bergqvist \& Ribeiro 1998, Ribeiro 2003), e Acre nos estados do Acre e Amazonas (Formação Solimões, Mioceno) (e.g. Ribeiro et al. 2013 e referências citadas). Em relação ao Quaternário, apesar da pequena diversidade

A
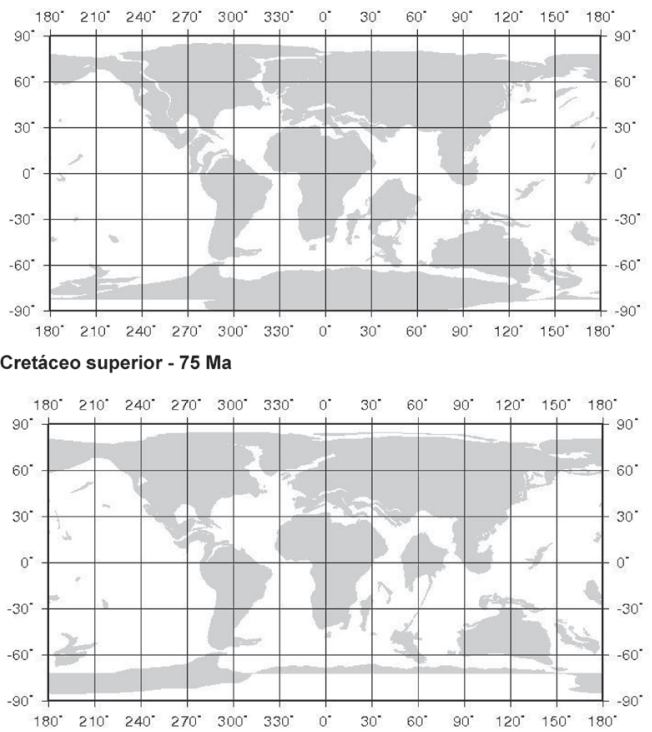

Eoceno - $50 \mathrm{Ma}$

C

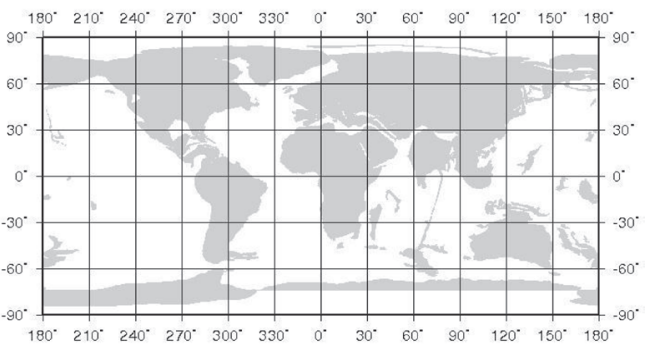

Oligoceno - $30 \mathrm{Ma}$

Fig. 1 Reconstrução paleobiogeográfica da Terra durante o Cretáceo superior, Eoceno e Oligoceno. Baseado em Ocean Drilling Stratigraphic Network (ODSN) Plate Tectonic Reconstruction Service. 
de ungulados nativos, há amplo registro desses por todo o país, sendo encontrados em barrancas de rios na Região Norte (Acre, Amazonas, Rondônia), em "tanques" (depressões do embasamento cristalino) da Região Nordeste, cavernas da Bahia, Ceará, Goiás, Mato Grosso, Minas Gerais, São Paulo, Paraná, Piauí e Rio de Janeiro, bem como em barrancas de arroios, rios e Planície Costeira do Rio Grande do Sul. Invariavelmente, as faunas extra-patagônicas do Paleógeno e Neógeno exibem significativas diferenças taxonômicas quando comparadas às clássicas localidades da Patagônia argentina.

No contexto da diversificação dos mamíferos placentários endêmicos da AS, destaca-se a ordem Notoungulata (Fig. 2), formada por ungulados herbívoros registrados a partir do Eoceno (55,8 Ma), no Itaboraiense (Oliveira \& Goin 2011) até o final do Pleistoceno/início do Holoceno (e.g. Cifelli 1985) (Fig. 3), com ampla distribuição por toda a AS, tendo alcançado a AC e AN durante o Pleistoceno. Dois gêneros emigraram para latitudes mais holárticas durante o Pleistoceno, após a formação do istmo do Panamá: Toxodon, que atingiu a AC (Honduras, Nicarágua e El Salvador) e, Mixotoxodon, que alcançou a Venezuela, Honduras, El Salvador e México (Van Frank 1957, Webb \& Perrigo 1984), sendo também reportado para os Estados Unidos (Lundelius et al. 2013).

\section{Notoungulados: os ungulados do Sul}

O registro mais antigo dos Notoungulata (do grego nótos $=$ sul + ungulado) é de Perutherium altiplanense do Paleoceno-Eoceno da localidade de Laguna Umayo, no Peru, e, embora não haja um consenso sobre as relações filogenéticas desse táxon, ele provavelmente está relacionado à ancestralidade dos demais notoungulados (Marshall et al. 1983, Sigé et al. 2004). Para o Eoceno da Argentina (Patagônia) são registrados os primeiros notoungulados da família Isotemnidae (Isotemnus) (Marshall et al. 1983, Woodburne et al. 2014). O grupo alcançou sua maior diversidade durante o Oligoceno (Tinguiririquense-Deseadense) (Cifelli 1985, Croft et al. 2008, Woodburne et al. 2014), e sofrido drástico declínio durante o Plioceno, até sua extinção no Pleistoceno superior - Holoceno inferior (Bond et al. 1995) (Fig. 3).

Os notoungulados formam um clado constituído por aproximadamente 100 gêneros, distribuídos em 10 famílias nas subordens Typotheria e Toxodontia (Figs. 2 e 3) (Billet 2011). Na subor-

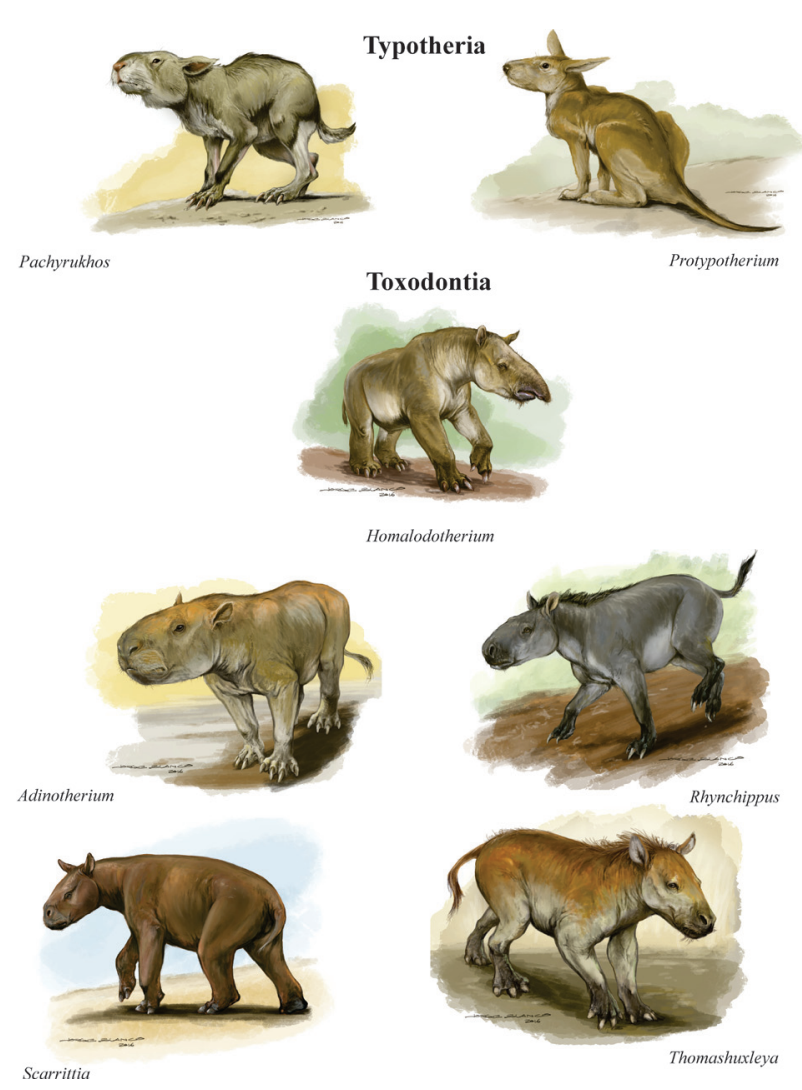

Fig. 2 Reconstituição artística de notoungulados tipotérios e toxodontes. Desenhos de Jorge Blanco.

dem Typotheria encontram-se formas de tamanho pequeno a médio, semelhantes a roedores e coelhos, que se tornou taxonomicamente diversa e numericamente abundante no Eoceno (Reguero \& Prevosti 2010). Já Toxodontia engloba animais de tamanhos pequeno, médio a bastante avantajado, incluindo megamamíferos com $1.000 \mathrm{Kg}$ ou mais (Elissamburu 2012) (Figs. 2 e 4).

Ao longo da evolução dos notoungulados, é possível observar redução dos incisivos, caninos e pré-molares em alguns grupos, com pré-molares e molares braquiodontes (dentes de coroa baixa e raiz) nas primeiras formas, evoluindo para dentes mesodontes (de coroa com altura intermediária e raiz), depois para proto-hipsodontes (de coroa alta, nos quais se observa crescimento contínuo até certa idade, havendo desenvolvimento de raízes no animal adulto). Finalmente alcançaram a dentição eu-hipsodonte, na qual os dentes crescem continuamente, nunca formando raízes durante toda a vida do animal (dentes que têm a forma de uma coroa muito alta, formando uma fuste dentária) (sensu Mones 1982). 


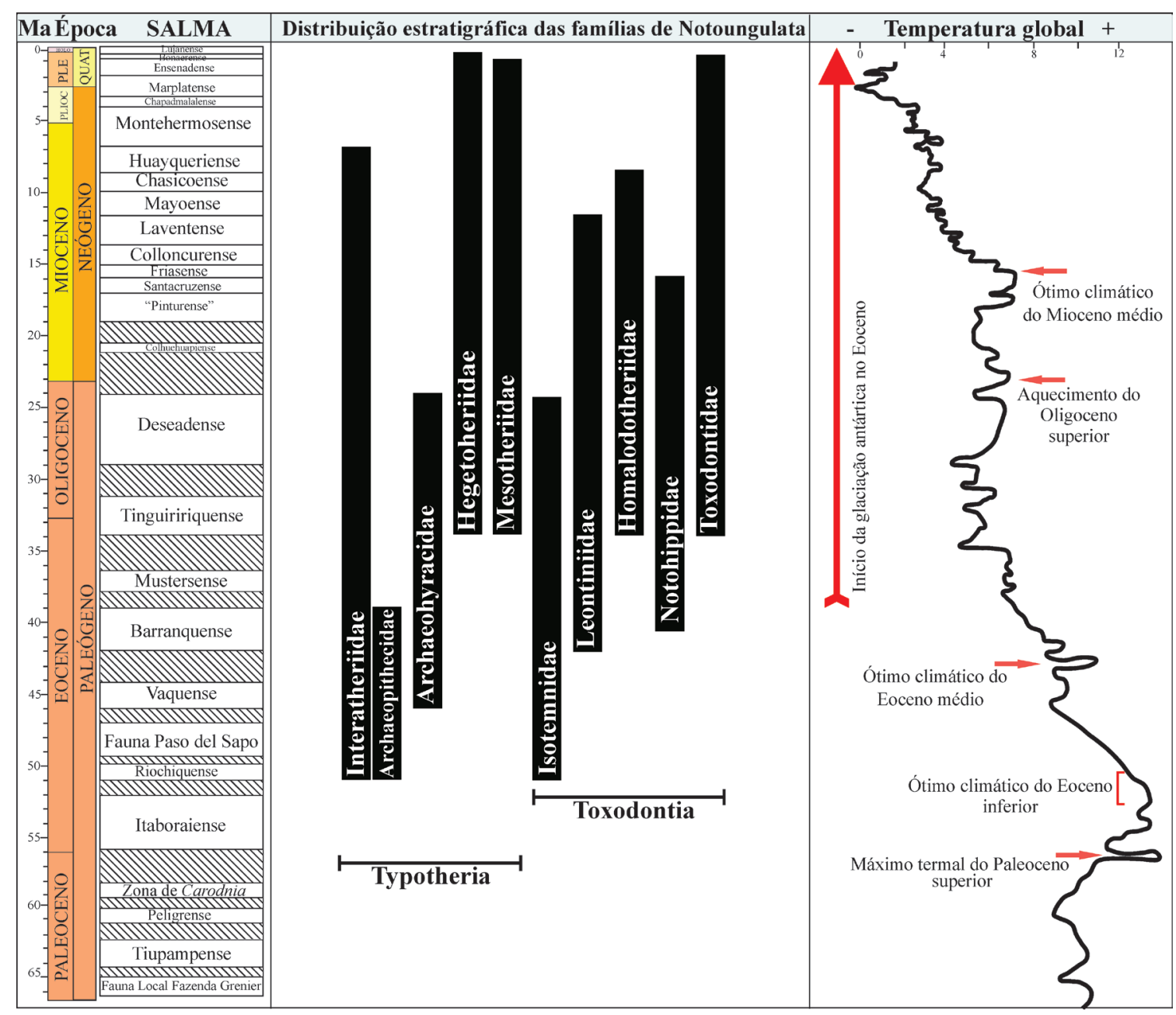

Fig. 3 Cronologia das Idades de Mamíferos Terrestres Sul-Americanos (SALMA) e distribuição estratigráfica das famílias Notoungulata da América do Sul, América Central e América do Norte, desde o Paleoceno até o Pleistoceno superior. Períodos e épocas conforme a Carta Estratigráfica Internacional (http://www.stratigraphy.org/ICSchart/ ChronostratChart2013-01.pdf). SALMA baseadas em Tejedor et al. (2009), Gelfo et al. (2009), Bond \& Deschamps (2010), Bond \& Gelfo (2010), Kramarz et al. (2010), Oliveira \& Goin (2011), Dunn et al. (2013) e Woodburne et al. (2014). Curva de temperatura global e principais eventos climáticos do Cenozoico retirados de Zachos et al. (2008).

\section{Os toxodontes sul-americanos no cenário cenozoico: aspectos paleoclimático $\mathrm{e}$ paleoambiental}

Earth and Life evolve together (Croizat 1958)

Dentre os toxodontes estão incluídos os grandes notoungulados, distribuídos entre as famílias Isotemnidae (Itaboraiense ao Deseadense), Notohippidae (Casamaiorense ao Santacruzense), Leontiniidae (Barranquense ao Laventense), Homalodotheriidae (Tinguiririquense ao Chasicoense), e Toxodontidae (Deseadense ao Lujanense) (Figs. 2 e 3), das quais apenas a última alcançou o Pleistoceno superior, com três gêneros remanescentes: Toxodon (Fig. 4), Piauhytherium e, Mixotoxodon, tendo este último gênero alcançado a AN (Lundelius et al. 2013). Cabe ressaltar que, alguns estudos (e.g. Shockey \& Flynn 2007) sugerem a possibilidade de que os isotemnídeos e os homalodoteriídeos formem um grupo monofilético, enquanto essa hipótese não é suportada pela análise filogenética realizada por outros (e.g. Billet 2011). A distinção entre as famílias é um tanto problemática, provavelmente os Homalodotheriidae evoluíram a partir dos Isotemniidae, tendo sofrido especialização muito rapidamente, através de modificações principalmente em seus membros locomotores, particularmente nas patas cujos cascos transformaram-se em garras. 


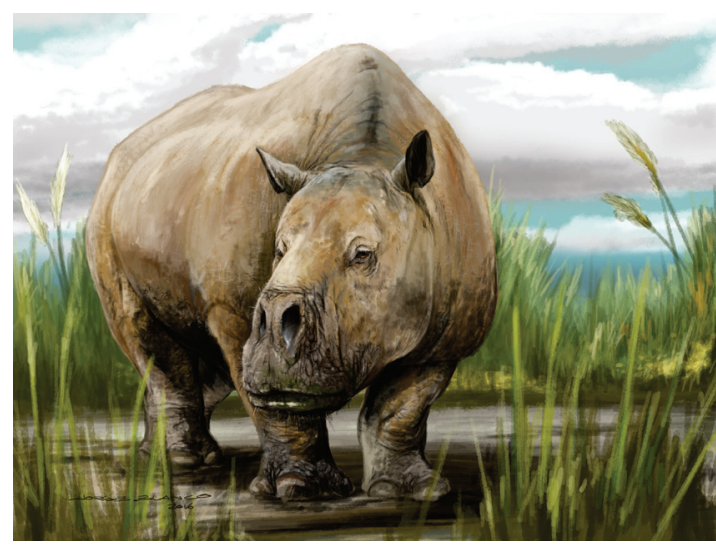

Fig.4 Reconstituição artística de uma paisagem do Pleistoceno sul-americano, com o notoungulado Toxodon, herbívoro de tamanho avantajado. Desenho de Jorge Blanco.

\section{Paleógeno}

O Paleógeno foi o maior período de aquecimento do Cenozoico, sendo que temperaturas globais mais elevadas iniciaram no Paleoceno, onde são registrados alguns pulsos hipertermais de curto período (na ordem de 10 mil anos). O mais impressionante foi aquele ocorrido no limite Paleoceno-Eoceno, denominado "Máximo termal do Paleoceno superior" (MTPS), sucedido pelo "Ótimo climático do Eoceno inferior" (OCEI) e, pelo "Ótimo climático do Eoceno médio" (OCEM). Um subsequente resfriamento ocorreu a partir do Eoceno, marcado pelo início da glaciação antártica (Zachos et al. 2008, Zachos et al. 2010, Woodburne et al. 2014) (Fig. 3).

\section{Paleoceno}

Embora não seja registrada a presença dos Toxodontia, os eventos climáticos e bióticos ocorridos durante o Paleoceno foram de grande importância para a dispersão e evolução dos ungulados nativos sul-americanos. Os notoungulados reportados foram provavelmente herbívoros ramoneadores lofodontes, adaptados a clima quente e úmido em ambientes tropicais florestados, caracterizados por grande diversidade florística (Wilf et al. 2013).

\section{Eoceno}

Para o início do Eoceno, são registrados climas subtropicais úmidos, com temperaturas oscilando em torno de $16^{\circ} \mathrm{C}$ a $19^{\circ} \mathrm{C}$, precipitações biestacionais e nível do mar elevado, coincidindo com o OCEI (Barreda \& Palazzesi 2007) (Fig. 3). Faunas de mamíferos do Itaboraiense do Brasil e Argenti- na enfrentaram o OCEI, tendo sofrido um grande aumento em sua diversidade, alcançando sua estrutura ecológica e taxonômica básica nesta idade (Woodburne et al. 2014). Nesta época, surgiram na Patagônia argentina, os primeiros notoungulados typotérios hipsodontes de tamanho médio, equivalentes a um cervo atual (Acropithecus no Riochiquense e Eohyrax no Vaquense) (Reguero \& Prevosti 2010, Woodburne et al. 2014). No entanto, em certas áreas restritas do interior da Patagônia teriam prevalecido condições mais quentes e secas, a julgar pelo registro paleoflorístico de anacardiáceas (Barreda \& Palazzesi 2007). Durante o Vaquense ocorre o OCEM, e ao final do Barranquense, inicia o resfriamento global (no Barranquense, prevaleceu clima quente, porém, houve resfriamento com o início da glaciação antártica (Kay et al. 1999), sendo registrada, uma importante mudança faunística, sobretudo entre os Toxodontia.

Os Toxodontia são primeiramente reportados para o Eoceno por meio de Isotemnus, do Riochiquense da Patagônia argentina (Tejedor et al. 2009), idade correspondente ao final do OCEI (Fig. 3). Os toxodontes da Patagônia argentina registrados durante o OCEM (Vaquense-Barranquense) são Anisotemnus, Pleurostylodon e Thomashuxleya, isotemnídeos braquiodontes com dentição similar a Isotemnus do Riochiquense, embora já exibam uma coroa mais elevada, bem como o notohippídeo Plexotemnus (Simpson 1967, Tejedor et al. 2009, López et al. 2010, Woodburne et al. 2014).

Durante a transição Eoceno-Oligoceno, a partir do registro dos Toxodontia, principalmente no que concerne à aquisição da hipsodontia, é possível distinguir, uma marcante renovação faunística relacionada a mudanças ambientais, principalmente associadas à Fase Diastrófica Inca da orogenia andina. Nessa fase os Andes austrais ainda incipientes são reativados, ocorrendo soerguimento da Patagônia Central (Marshall \& Sempere 1993) e a abertura do Mar da Tasmânia pela Passagem de Drake. Como consequência, há mudança no fluxo das águas da Antártica e queda significativa da temperatura e do nível do mar. Essa transição é marcada por taxas de extinção mais elevadas em linhagens arcaicas (ungulados nativos braquiodontes), levando concomitantemente ao predomínio de comunidades caracterizadas por aspectos mais modernos. Por exemplo, observa-se o aumento da diversidade de ungulados nativos hipsodontes e, uma regularidade nas classes de tamanho corporal, eventos registrados principalmente no sul da Patagônia (Ortiz- 
-Jaureguizar \& Cladera 2006), e no Chile (Flynn et al. 2003). Contudo, no noroeste da Argentina, durante o Eoceno médio, observa-se predomínio de táxons braquiodontes, possivelmente associados a ambientes fechados, quentes e úmidos nesta região (García-López et al. 2017).

O cenário climático e paleoambiental proposto para o Eoceno inferior e médio, com a existência de ambientes de floresta subtropical, desenvolvidos sob climas quentes e úmidos corrobora a presença de comunidades de mamíferos com maior abundância de ramoneadores, bem como de insetívoros e onívoro-insetívoros, e baixa diversidade de animais de dieta mista e pastadores (Ortiz-Jaureguizar \& Cladera 2006). Já para o final do Eoceno (Barranquense-Tinguiririquense), ocorre a transição de condições climáticas mais quentes para resfriamento e queda do nível dos oceanos, coincidindo com o aumento da diversidade de espécies de dieta mista de pastadores, sugerindo aumento da aridez e maior porcentagem de gramíneas nas comunidades vegetais (Ortiz-Jaureguizar \& Cladera 2006). A época, a hipsodontia evoluiu paralelamente ao menos em seis famílias de notoungulados: Archaeohyracidae, Hegetotheriidae, Interatheriidae, Mesotheriidae, Notohippidae e Toxodontidae (Patterson \& Pascual 1968, Simpson 1980, Flynn et al. 2003, Strömberg et al. 2013).

\section{Oligoceno}

Os eventos climáticos e bióticos resgistrados para a transição Eoceno-Oligoceno configuram entre os mais significativos da história da vida na Terra, influenciando substancialmente o clima durante o Oligoceno através do: 1 , decréscimo na precipitação média anual; 2 , decréscimo na temperatura média anual; 3 , decréscimo na temperatura média mais fria mensal e, 4 , aumento na amplitude das temperaturas média mensais (Fig. 3) (Kay et al. 1999). Este acentuado resfriamento é corroborado pela substituição de comunidades vegetais megatérmicas predominantes no Eoceno por bosques meso e microtérmicos de Nothofagus e podocarpáceas, sendo os táxons indicadores de ambientes xéricos bastante escassos nesta época (Barreda \& Palazzesi 2007).

As mudanças ambientais e climáticas registradas para este momento estão bem documentadas na fauna oligocênica do Tinguiririquense, localizada próximo à localidade de Termas del Flaco, na Formação Abanico, região central do Chile, compreendendo a mais antiga assembleia de hábitats abertos da AS, composta por pastagens e/ou savanas arborizadas, com predomínio de herbívoros hipsodontes (Flynn et al. 2003, Reguero et al. 2010). Outras faunas, as quais também é atribuída idade Tinguiririquense podem ser encontradas na Patagônia (Gran Barranca, "Astraponotéen le plus supérieur"), em outras pequenas localidades nas províncias de Chubut e Rio Negro, na Argentina (Croft et al. 2008), e possivelmente Peru (Fauna de Santa Rosa; Ribeiro et al. 2013), e no Brasil (Formação Guabirotuba; Sedor et al. 2017). À exceção do isotemnídeo Rhyphodon, grandes notoungulados braquiodontes são pouco representativos no vale do Tinguiririca (Flynn et al. 2003, Croft et al. 2008). A predominância de mamíferos hipsodontes corrobora a proposta de ambientes mais abertos e climas mais frios para estas comunidades, como por exemplo, o notohoppídeo Eomorphippus, um dos mais antigos notoungulados Toxodontia a desenvolver dentição hipsodonte e adaptação a hábitos cursoriais, devido às suas patas tridáctilas (López et al. 2010).

Ao final do Oligoceno (Deseadense), houve modificação na direção da convergência entre placas Sul-americana e de Nazca, induzindo importantes modificações no arco andino, reativando o principal cinturão magmático. Consequentemente, a atividade ígnea expandiu-se sobre grandes áreas, invadindo a porção centro-oeste da Argentina, Bolívia e Peru (Ortiz-Jaureguizar \& Cladera 2006).

As principais localidades fossilíferas para esta idade encontram-se na Patagônia argentina (províncias de Chubut e Santa Cruz) e Bolívia (Salla), embora também sejam registradas em outras regiões da Argentina (nas províncias de Mendoza, Entre Ríos e Corrientes), Brasil e Uruguai (e.g. Marshall et al. 1983, Ubilla et al. 1994, Bond et al. 1998). Do Barranquense até o Deseadense, houve um processo de "modernização" da fauna de mamíferos sul-americanos, quando se observa a extinção de ao menos seis famílias de ungulados nativos paleógenos mais primitivos (Notoungulata Henricosborniidae, Notostylopidae, Oldfieldthomasiidae e Archaeohyracidae, "Condylarthra" Didolodontidae e Astrapotheria Trigonostylopidae), culminando na radiação adaptativa e surgimento de novas linhagens dentre os grupos endêmicos. Destacam-se ainda para esta idade aparecimento de variados tipos pastadores (Notohippidae) e, primeiro registro de Toxodontidae (Marshall et al. 1983, Kay et al. 1999, Pascual \& Ortiz-Jaureguizar 2007). 


\section{Neógeno}

\section{Mioceno}

Muitas informações são provenientes do registro da Patagônia argentina, onde depósitos sedimentares marinhos e continentais representam o maior componente da sucessão estratigráfica do Neógeno (Pascual \& Ortiz-Jaureguizar 1990, 2007). No Mioceno são registradas importantes mudanças climáticas e ambientais associadas ao aumento da temperatura global (Zachos et al. 2008), a flutuações eustáticas dos níveis oceânicos (Miller et al. 2005) e grandes eventos geotectônicos. Tais eventos estão relacionados ao aumento da taxa de subducção entre as placas de Nazca e Sul-americana, os quais levaram ao principal soerguimento dos Andes, e a um contraste entre a biota ocidental e oriental do continente (Ortiz-Jaureguizar \& Cladera 2006, Pascual \& OrtizJaureguizar 2007).

Do início do Mioceno (23 Ma) até o "Ótimo climático do Mioceno médio" (OCMM) (16 Ma), o clima tornou-se progressivamente mais quente e chuvoso (Ortiz-Jaureguizar \& Cladera 2006). É registrada mudança na composição vegetal, que exibe equilíbrio entre as pastagens e as florestas, provavelmente representadas por savanas-parque com predomínio de formas herbáceo-arbustivas e áreas de hábitats abertos, corroborando os registros de elevação da aridez e, dando início a uma aparência mais moderna às comunidades vegetais (Ortíz-Jaureguizar \& Cladera 2006, Barreda \& Palazzesi 2007, Strömberg et al. 2013).

Foi bastante frequente durante todo o Mioceno a ocorrência de notoungulados pastadores cursoriais e de quatro famílias que alcançaram a eu-hipsodontia, sendo sua presença geralmente interpretada como indicativa de hábitos pastadores em hábitats abertos (Simpson 1980, Cifelli 1985). Quanto aos Toxodontia, os Homalodotheriidae, embora pouco diversos, ainda persistem até o Chasicoense, quando é reportado o último aparecimento da família para a Província de Buenos Aires, sendo que a partir desta idade, o registro de mamíferos terrestres é quase que exclusivamente de áreas extra-patagônicas (Macfadden et al. 1996, Flynn et al. 2003).

A partir do Mioceno médio ocorre um aumento da diversidade e abundância de vegetação xerofítica, bem como extinção de elementos megatérmicos e não-sazonais, provavelmente associados a fatores climáticos e tectônicos, dentre eles a ação das primeiras subfases da fase diastrófica Quechua da orogenia andina (Pascual 2006), que levaram à sazonalidade e aridez extremas (Barreda \& Palazzesi 2007, Strömberg et al. 2013). A partir do Santacruzense é possível observar a diversificação de toxodontídeos eu-hipsodontes, coincidindo com o OCMM, sendo que este cenário persiste através do predomínio de formas pastadoras no Mioceno médio.

Nas faunas do Mioceno inferior e médio, os Toxodontidae parecem substituir os Notohippidae. Os toxodontídeos já haviam iniciado o desenvolvimento da eu-hipsodontia, a partir do final do Deseadense-Colhuehuapiense, prosseguindo durante o Santacruzense, finalizando com Palyeidodon obtusum no Colloncurrense (Madden 2015). Pericotoxodon, do Mioceno inferior do Equador, é o mais antigo registro da presença de dentes eu-hipsodontes em Toxodontidae fora da Patagônia (Madden 2015). Os "toxodontídeos avançados" exibiam uma considerável variação em relação ao tamanho da coroa dentária, de pequeno (e.g. Hyperotoxodon) a grande (e.g. Palyeidodon). Antes do final do Mioceno médio, a diversidade taxonômica e morfológica da família aumentou com o surgimento e diversificação de táxons com coroas simplificadas e de crescimento contínuo. Os Toxodontidae são os únicos Toxodontia registrados a partir do Huayqueriense $(\sim 8 \mathrm{Ma})$, bastante frequentes e bem representados em localidades fossilíferas do noroeste e nordeste da Argentina, Brasil, Bolívia, Uruguai e Venezuela. O surgimento de formas de tamanho avantajado e eu-hipsodontes, de hábitos pastadores estritos, e, desaparecimento de formas ramoneadoras (Homalodotheriidae) a partir desta idade, indica que ambientes florestados subtropicais tornaram-se raros ou extintos e, as planícies austrais sofreram expansão, com predomínio das savanas herbáceas e das pastagens (Patterson \& Pascual 1972, Ortiz-Jaureguizar \& Cladera 2006, Ribeiro et al. 2013). Importantes registros de Toxodontia (Leontiniidae, Notohippidae e Toxodontidae) provêm da Amazônia brasileira, na Formação Solimões, Bacia do Acre, aos quais é atribuída classicamente como da idade Huayqueriense-Montehermosense, porém os leontinídeos, notohipídeos e alguns toxodontídeos possivelmente pertençam a idades mais antigas equivalentes, por exemplo, ao Laventense da Colômbia (Ribeiro et al. 2013). 


\section{Plioceno}

Após milhões de anos de isolamento, durante o final do Plioceno, o continente sul-americano se uniu ao norte-americano pela formação do Istmo do Panamá, ocorrendo resfriamento na região do Ártico devido ao fortalecimento das correntes de Humboldt e do Golfo e, o fim da circulação de correntes marinhas primitivas de águas quentes que atravessavam o planeta de leste a oeste, levando ao Último Máximo Glacial (Leigh et al. 2013). Estabeleceu-se então uma conexão terrestre entre as faunas austrais e holárticas, permitindo um importante evento migratório entre ambos continentes, denominado "Grande Intercâmbio Biótico Americano" (Marshall et al. 1982, Webb 2006). Alguns grupos de mamíferos migraram do Hemisfério Norte, representando hoje cerca de $50 \%$ dos gêneros viventes na AS (Leigh et al. 2013), havendo a partir dessa época um drástico declínio da diversidade de ungulados nativos sul-americanos.

\section{Pleistoceno}

Observa-se durante o Pleistoceno a continuidade da redução dos notoungulados iniciada no Plioceno, representados pelos Toxodontidae e os typotérios Hegetotheridae e Mesotheridae pastadores. As localidades fossilíferas pleistocênicas são bastante abundantes por toda AS, cujo registro da presença de toxodontídeos se estende ao Pleistoceno da AC e AN. Durante o Pleistoceno superior ocorre uma extinção em massa dos grandes ungulados nativos sul-americanos, para a qual são propostas inúmeras hipóteses, entre as quais a relação da entrada de patógenos introduzidos pelos imigrantes norte-americanos após o "Grande Intercâmbio Biótico Americano" (Ferigolo 1999) e, interferência humana através da caça associada ao particular cenário climático, ecológico e biogeográfico da AS estabelecido pelos períodos interglaciais (Cione et al. 2003).

\section{Aspectos morfológicos e microestruturais da dentição dos notoungulados Toxodontia}

\section{Os Notoungulata e o surgimento da hipsodontia}

Tanto os Toxodontia quanto os Typotheria exibem uma tendência a evoluir, de um sistema mastigatório generalizado, com dentição completa, sem diastema, com molares e pré-molares braquiodontes, a formas muito especializadas, algumas com incisivos hipertrofiados, padrões oclusais da coroa simplificados e eu-hipsodontia (Ameghino 1887, Simpson 1967, Cifelli 1985). O exemplo dos notoungulados é notável, já que é possível observar em faunas eocênicas uma "hipsodontia precoce". As hipóteses concernentes ao desenvolvimento da hipsodontia, em sua maioria, relacionam a elevação da altura da coroa dentária ao aumento da vida funcional do dente devido ao desgaste causado pela ingestão de fitólitos, abundantes em gramíneas (e.g. Fortelius 1985, Janis 1988, Janis \& Fortelius 1988). Por esta razão, muitos autores relacionam o surgimento das gramíneas na $\mathrm{AS}$, há $40 \mathrm{Ma}$, à presença destes ungulados, aproximadamente $10 \mathrm{Ma}$ antes do que registrado para a AN (Patterson \& Pascual 1972, Simpson 1980, Stebbins 1981, Kay et al. 1999, Macfadden 2000).

Muito do que se sabe sobre o surgimento das gramíneas na AS vem de localidades fossilíferas da Patagônia argentina (Strömberg et al. 2013). Entretanto, alguns autores rejeitam a hipótese de que os ecossistemas dominados por gramíneas surgiram primeiramente na Patagônia e que a evolução da hipsodontia foi determinada pela dispersão das pastagens na AS. Através do registro de fitólitos de Gran Barranca (Formação Sarmiento, Província de Chubut), Strömberg et al. (2013) propõem que, embora as pastagens características de hábitats abertos já estivessem presentes na AS desde o Eoceno médio, elas eram os componentes florísticos menos abundantes, ao contrário das florestas, entre 40 e 18 milhões Ma. Paisagens dominadas por gramíneas só foram observadas há 18,5 Ma. nessa região, contrariando estudos prévios que atribuem o surgimento de pastagens há $40 \mathrm{Ma}$. A contínua reposição de solos abrasivos ricos em cinza vulcânica, trazida pelo vento de vulcões andinos e intracontinentais ativos, pode ter atuado como pressão seletiva ao desenvolvimento da hipsodontia (Reguero et al. 2010, Strömberg et al. 2013).

A variação da morfologia dentária, principalmente no que concerne à aquisição da hipsodontia, obervada em especial aqui nos Toxodontia, possivelmente se relaciona a alterações climáticas e tectônicas ao longo do Cenozoico. A aquisição de dentição eu-hipsodonte em muitas linhagens torna os Notoungulata um excelente modelo para testar hipóteses de relação entre altura da coroa dentária e preferência de dieta e hábitat em mamíferos extintos, sendo considerado um dos melhores exemplos de tendência macroevolutiva (Simpson 1953). A hipsodontia é geralmente considerada como uma 


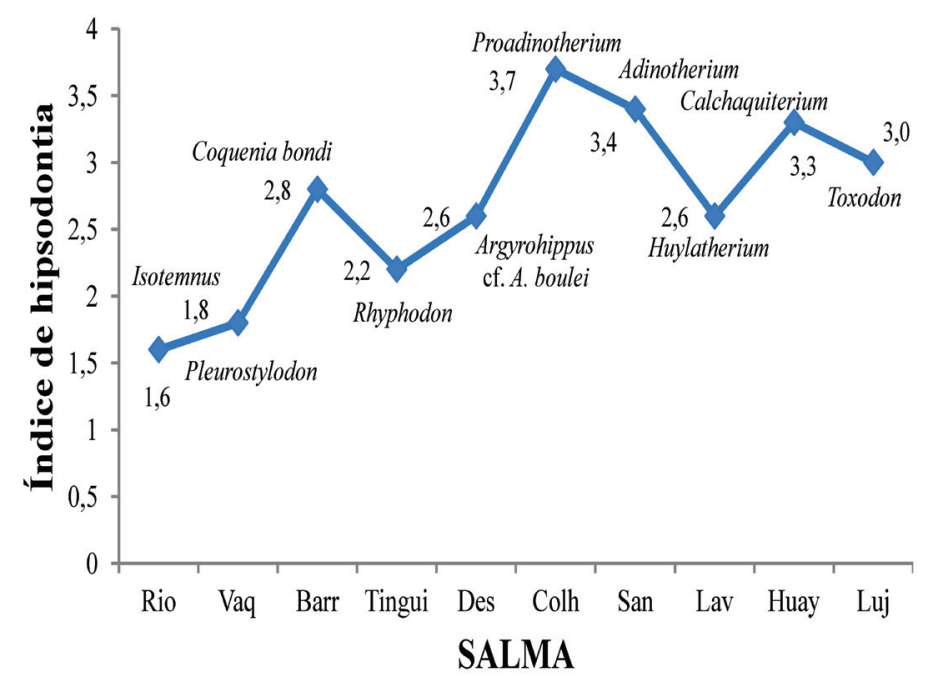

Fig. 5 Gráfico representativo dos índices de hipsodontia para toxodontes a partir do Eoceno (Riochiquense) até o Pleistoceno superior (Lujanense). Rio, Riochiquense; Vaq, Vaquense; Barr, Barranquense; Tingui, Tinguiririquense; Des, Deseadense; Colh, Colhuehuapiense; San, Santacruzense; Lav, Laventense; Huay, Huayqueriense; Luj, Lujanense.

especialização morfológica surgida como resposta adaptativa ao consumo de gramíneas abrasivas, sendo sua presença indicativa de hábitos pastadores em ambientes abertos (e.g. Van Valen 1960, Macnaughton et al. 1985, Macfadden \& Cerling 1996).

Segundo o índice de hipsodontia, calculado através da razão entre a altura e a largura da coroa do m3 (Van Valen 1960), indivíduos que apresentam valor entre 1 e 1,5 são classificados como braquiodontes, enquanto aqueles com índice entre 1,5 e 3 são mesodontes, e, são ditos hipsodontes (proto e eu-hipsodontes) quando os valores são maiores que 3 . Animais braquiodontes são considerados ramoneadores (browsers), por alimentarem-se de folhas, caules e frutos, e, animais com dentição proto-hipsodonte ou eu-hipsodonte são considerados pastadores (grazers), alimentando-se principalmente de gramíneas e outras vegetações de hábitats abertos, podendo alguns animais exibir hábitos mistos (mixed-feeders) (Cifelli 1985). Janis (1988) foi quem primeiro testou a relação do índice de hipsodontia com as preferências alimentares em ungulados viventes e, desde então, o grau de hipsodontia tem sido amplamente utilizado para inferir hábitos alimentares em notoungulados (e.g. Kay \& Madden 1997a, b, Fortelius \& Solounias 2000, Macfadden 2000). Entre as famílias de Toxodontia, é possível observar um notável aumento do índice de hipsodontia desde o Riochiquense até o Lujanense (Fig. 5).

\section{Métodos utilizados para inferir hábitos alimentares em ungulados extintos}

Além do uso do índice de hipsodontia na determinação de hábitos alimentares em mamíferos herbívoros, inúmeros autores correlacionam a morfologia crânio-dentária a adaptações ecológicas para inferir dieta em táxons atuais e fósseis (Janis \& Ehrhardt 1988, Solounias \& Moelleken 1993, Janis 1995, Mendoza et al. 2002).

Strömberg (2006) sugere cautela ao relacionar a hipsodontia a hábitos alimentares em herbívoros extintos. Segundo Townsend \& Croft (2008), as razões por detrás do paralelo desenvolvimento da hipsodontia em várias linhagens de Notoungulata ainda são desconhecidas, havendo uma variedade de hipóteses relacionadas à origem desta tendência. Simpson (1980) sugeriu que os notoungulados eram geneticamente predispostos a desenvolver a hipsodontia mais cedo do que outros ungulados do mundo. Outros autores propuseram que a hipsodontia foi uma resposta à cinza vulcânica sobre as plantas ingeridas pelos ungulados e outros herbívoros sul-americanos (Flynn et al. 2003, Croft et al. 2008, Strömberg et al. 2013, Madden 2015). Para uma maior discussão ver Madden (2015, p. 284).

A hipsodontia é geralmente reconhecida como uma adaptação aos hábitos de pastoreio, sendo que as gramíneas aumentariam o desgaste dentário devido às suas propriedades endógenas (presença de fibras, fitólitos) e exógenas (presença de argila, silte e areia). Porém, não há um consenso se o aumento da altura da coroa dentária está correlacionado com a mastigação de fibras e sílica das gramíneas, ou à ingestão de abrasivos externos presentes nas mesmas, ou mesmo, se ambos os fatores influenciam neste processo (Stebbins 1981, Williams \& Kay 2001). Williams \& Kay (2001) afirmam que tanto a dieta quanto a presença de areia e cinza durante a mastigação são fatores que atuam como efeitos aditivos na evolução da coroa dentária em ungulados. Janis $(1988,1995)$ atribui a hipsodontia a preferência de forrageio em hábitats abertos, por animais que se alimentam de plantas baixas e, que possam ter sido cobertas por pó abrasivo ou areia.

Tem sido aceito amplamente que o aumento da altura da coroa é um mecanismo para aumentar a 
vida funcional do dente frente ao intenso desgaste, não havendo estudos para mensurar a taxa de desgaste dentário (em todos os tecidos dentários) e sua relação com os hábitos alimentares (e.g. Williams \& Kay 2001). Por esta razão, a utilização da altura da coroa dentária por si só não pode determinar preferências alimentares em ungulados (Janis 1988), não sendo possível correlacionar o surgimento da hipsodontia à expansão das gramíneas, devendo haver análise de fatores paleoecológicos e paleoclimáticos associados, e, considerada a presença de areia, argila, silte, pó e, até mesmo, cinzas provenientes de atividade vulcânica (Williams \& Kay 2001, Kaiser et al. 2013, Strömberg et al. 2013).

Além disso, nem sempre é possível observar entre os notoungulados eu-hipsodontes uma dieta restrita a gramíneas, podendo haver hábitos ramoneadores ou mistos (Macfadden 2005, Dantas et al. 2013, Lopes et al. 2013). A hipsodontia não está correlacionada apenas à dieta, mas a inúmeros outros fatores, como índice de precipitação (Eronen et al. 2010a, b), hábitats abertos (Mendoza \& Palmqvist 2008) e altura do forrageio em relação ao solo (Codron et al. 2007, 2008), independentemente da abundância de gramíneas (Williams \& Kay 2001, Damuth \& Janis 2011, Strömberg et al. 2013).

\section{Relação do surgimento da hipsodontia nos Toxodontia e o cenário climático e ambiental}

Ao longo da história evolutiva dos mamíferos herbívoros, o maior problema enfrentado por estes animais é o desenvolvimento de um mecanismo em que haja maior duração da vida útil do dente em resposta ao intenso desgaste provocado por dieta herbívora abrasiva. Com isso, houve o surgimento do aumento da coroa dentária e, para que os alvéolos comportassem o aumento da dimensão dos dentes, observa-se, não apenas em notoungulados, uma maior curvatura, principalmente dos molares superiores. O aumento da curvatura dos dentes constitui-se em um equivalente funcional da "hipsodontia unilateral", na qual há um maior desgaste na face bucal do esmalte em relação à lingual (Koenigswald 2011).

Ao longo da história evolutiva dos Toxodontia observa-se uma tendência à simplificação dos acidentes coronários na superfície oclusal dos pré-molares e molares, o que pode estar associado a um aumento na velocidade das taxas de erupção dentária em táxons mais derivados (Madden 2015).

Outra importante característica observada na evolução dos toxodontídeos "avançados" é a redução ou perda da dobra do esmalte lingual e fossétidas, tanto nos molares superiores quanto nos inferiores. Este caráter está relacionado a necessidades mecânicas e relacionadas ao desenvolvimento do aumento da altura da coroa (Koenigswald 2011). Porém, a redução ou perda destas dobras ocorre em distintos padrões nos diferentes toxodontídeos "avançados", parecendo não estar relacionada ao aumento da altura da coroa (Madden 1997, 2015). A simplificação da morfologia oclusal dos Toxodontidae observada ao longo de sua história evolutiva também pode estar relacionada ao fato da fase ontogenética 1 ser suprimida em detrimento da fase 2, para aumento da altura da coroa (Koenigswald 2011).

\section{Aspectos microestruturais da dentição dos Toxodontia}

O esmalte dos mamíferos é a substância mais dura do corpo, altamente mineralizado, composto por grupos de cristais de hidroxiapatita similarmente orientados e contendo $97 \%$ de sais de cálcio e apenas 3\% de água e matéria orgânica (Carlson 1990), característica conveniente para o processo de mastigação. Koenigswald \& Clemens (1992) classificaram hierarquicamente a microestrutura do esmalte, identificando quatro níveis estruturais: 1 , cristais, 2, prismas, 3 , tipos de esmalte e, 4, organização dos diferentes tipos de esmalte, determinada pelo arranjo de grupos de prismas em um dente (denominada "Schmelzmuster"). A organização dos diferentes tipos de esmalte pode fornecer importantes informações sobre aspectos filogenéticos e/ou acerca da biomecânica do processo mastigatório.

Mudanças na morfologia da coroa dos Toxodontia associadas ao desenvolvimento da hipsodontia também podem ser observadas na morfologia microestrutural do esmalte dentário, que se torna adaptado ao consumo de dietas mais abrasivas (Fortelius 1985, Maas 1997, Braunn et al. 2014).

Em toxodontes braquiodontes a mesodontes (Eoceno-Oligoceno), são observadas microestruturas primitivas, nas quais predomina o esmalte radial (e.g. Rhyphodon) e as bandas transversais pouco desenvolvidas (Isotemnus e Puelia), nas quais o ângulo de inclinação entre os prismas é baixo, indicando que ainda não ocorreu adaptação biomecânica para a hipsodontia (Koenigswald et al. 1987, Lindenau 2005) (Fig. 6). A partir do Oligoceno (Tinguiririquense), em formas 

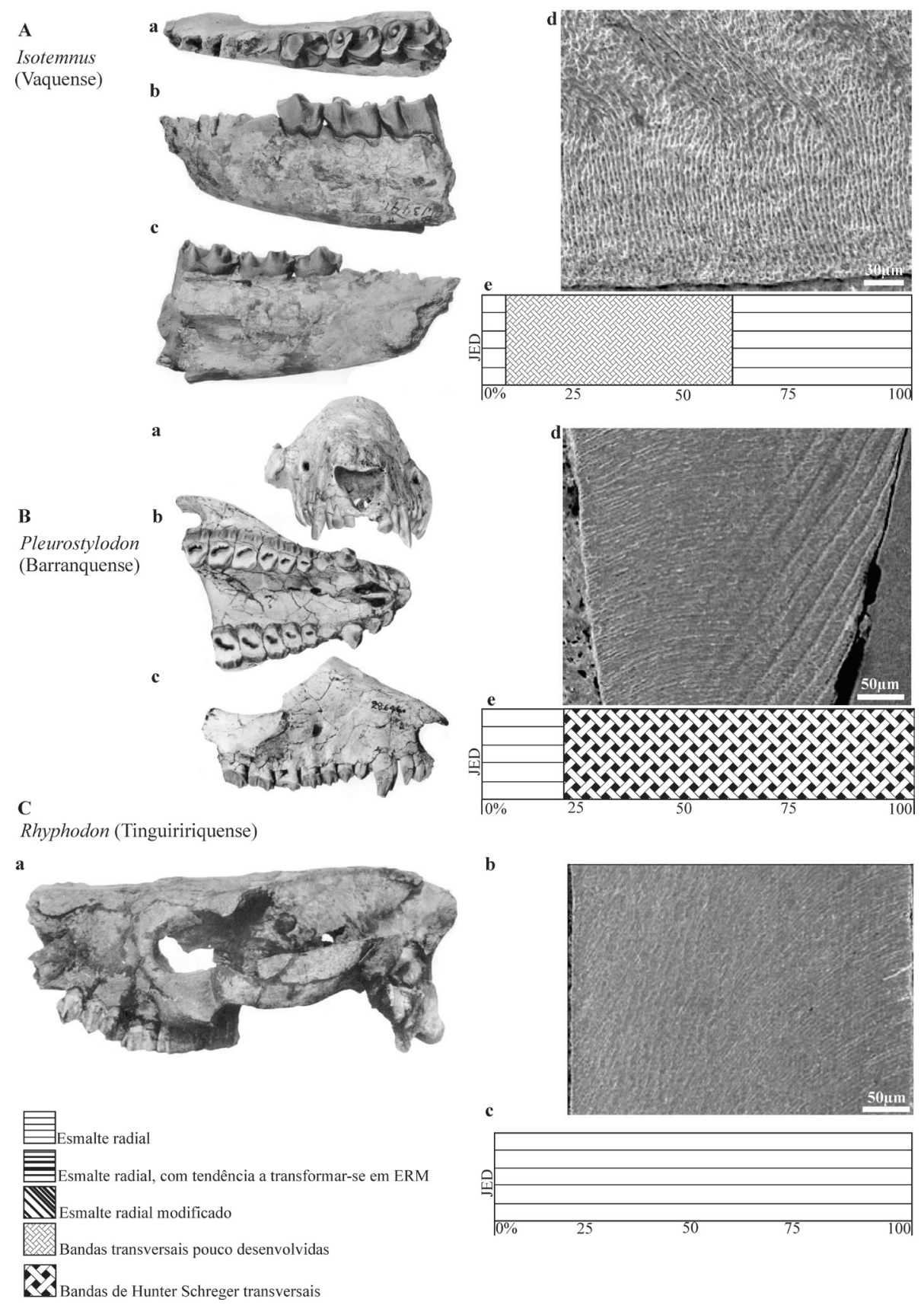

Fig. 6 Espécies de Toxodontia (Isotemnidae) do Neógeno sul-americano. Eletromicrografias de varredura de secções transversais e longitudinais em molares superiores e inferiores de toxodontes isotemnídeos ao longo do Cenozoico. Junto às eletromicrografias encontram-se diagramas representando a microestrutura do esmalte, com as zonas deste tecido observadas nestas espécies A, Isotemnus primitivus (Casamaiorense - Vaquense-?); a, mandíbula esquerda com p4-m2 em vista oclusal; b, vista lateral; c, vista lingual; d, eletromicrografia de secção transversal do molar inferior; e, diagrama ilustrando a microestrutura do esmalte em molar inferior; B, Pleurostylodon modicus (Barranquense); a, crânio em vista frontal; b, vista ventral; c, vista lateral direita; d, eletromicrografia de secção longitudinal do molar superior; e, diagrama ilustrando a microestrutura do esmalte em molar superior; C, Rhyphodon (Tinguiriquense); a, crânio em vista lateral esquerda; b, eletromicrografia de secção longitudinal do molar superior; c, diagrama ilustrando a microestrutura do esmalte em molar superior. Os diagramas representam a proporção de cada zona do esmalte desde a junção esmalte-dentina (JED) até à porção externa do dente. Modificado de Fortelius (1985) e Lindenau (2005). Fotografias dos espécimes retiradas de Simpson (1967, lâminas 29, 24 e 39), e eletromicrografias de Lindenau (2005). 
proto e eu-hipsodontes, é possível observar três tipos de esmalte: uma camada interna com o esmalte radial modificado, sucedida pelas bandas de Hunter-Schreger, e, pelo esmalte radial na porção mais externa do esmalte (Lindenau 2005, Braunn et al. 2014).

O esmalte radial modificado caracteriza-se por fileiras radiais de prismas ascendentes separadas por largas placas de matriz interprismática, nas quais os cristais são perpendiculares aos prismas. Este tipo de esmalte evoluiu em inúmeras ordens de mamíferos herbívoros hipsodontes por convergência, como uma adaptação estrutural devido às forças radiais de tensão mastigatória, que se concentram no esmalte interno, adjacente à junção esmalte-dentina, contrapondo-se aos impactos (Pfretzchner 1992). Em formas intermediárias de Toxodontia observa-se esmalte radial, porém, com tendência a transformar-se em esmalte radial modificado (e.g. Periphragnis, Fig. 7) (Lindenau 2005).

A zona do esmalte composta pelas bandas de Hunter-Schreger representa um tipo de esmalte mais derivado, caracterizado pela intersecção entre os prismas, sendo estes orientados paralelamente uns aos outros, formando um ângulo com os prismas das zonas adjacentes, normalmente distribuídos transversalmente ao eixo de crescimento do dente (Koenigswald \& Sander 1997). As bandas de Hunter-Schreger parecem ter evoluído independentemente em muitas ordens de mamíferos, e sua ocorrência em animais de grande tamanho corporal tem sido sistematicamente interpretada como uma adaptação ao aumento das forças de tensão geradas na mastigação, previnindo fraturas no esmalte, porém, são menos resistentes ao desgaste (Koenigswald et al. 1987). Em táxons com índice de hipsodontia mais alto (Periphragnis, Scarrittia, Toxodon e Nesodon), a área ocupada pelas bandas transversais é maior (Figs. 7 e 8 ).

O esmalte radial é o mais primitivo, encontrado na maioria dos mamíferos mesozoicos, no qual os prismas distribuem-se na zona mais externa, radialmente em relação à junção esmalte-dentina (Koenigswald \& Clemens 1992), e está relacionado à resistência a forças abrasivas, parecendo reduzir seus efeitos, especialmente quando superfícies oclusais opostas deslizam umas sobre as outras (Rensberger \& Koenigswald 1980, Boyde \& Fortelius 1986). Embora primitivo, o esmalte radial é efetivo na manutenção de superfícies cortantes pontiagudas. Surpreendentemente, Rhyphodon, do Tinguiririquense, fauna na qual predominam herbívoros hipsodontes (Flynn et al. 2003) e com índice de hipsodontia relativamente alto, apresenta predomínio do esmalte radial. Neste caso, é importante que sejam considerados outros fatores que também influenciam no desenvolvimento do tipo de esmalte dentário, como a direção e força aplicada ao movimento mastigatório, os itens alimentares disponíveis, a posição em que se encontra o esmalte analisado na coroa e, a espessura deste tecido.

\section{Considerações finais}

Este artigo, além de sintetizar informações sobre evolução morfológica dentária em Notoungulata, sobretudo no que concerne aos toxodontes, analisa de que maneira as modificações paleoclimáticas e paleoambientais ocorridas ao longo do Cenozoico influenciaram sobre os aspectos macro e microestruturais do grupo, principalmente no que concerne à aquisição da hipsodontia. Devido ao fato dos Toxodontia terem sofrido grande diversificação ao longo do Cenozoico, o conhecimento de sua paleobiologia é de grande importância para levantamento de hipóteses quanto ao paleoambiente em que estes animais viveram e, por haver uma estreita relação entre sua morfologia dentária e as alterações climáticas e ambientais. Fazem-se necessários estudos comparativos futuros entre espécimes de táxons provenientes de regiões austrais e neotropicais, bem como de distintas idades, utilizando dados macroscópicos e microscópicos associados a análises isotópicas, a fim de tecer inferências acerca da provável influência ambiental sobre o desenvolvimento dentário nestes animais.

Estudos anteriores sobre a dentição de ungulados sul-americanos são limitados quase exclusivamente à morfologia dentária dos respectivos táxons. Estudos sobre a microestrutura do esmalte entre os Toxodontia são raros, e constituem uma importante ferramenta para determinar suas características biomecânicas, tecer inferências sobre os hábitos alimentares dos animais, reconstruir ritmos biológicos, bem como para estudos sobre suas relações filogenéticas.

\section{Agradecimentos}

As autoras agradecem aos Doutores Jorge Ferigolo, Richard Harold Madden, Daniela Sanfelice e César Leandro Schultz pelas discussões e contribuições para com este estudo. Ao Centro de Microscopia e Microanálise da Universidade Federal do Rio Grande do Sul pela oportunidade de realizar 
A Periphragnis

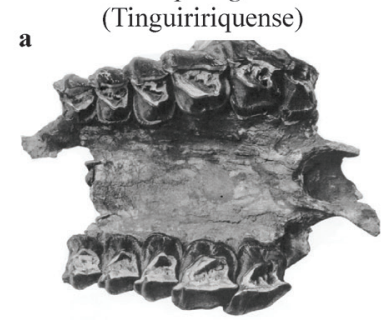

b
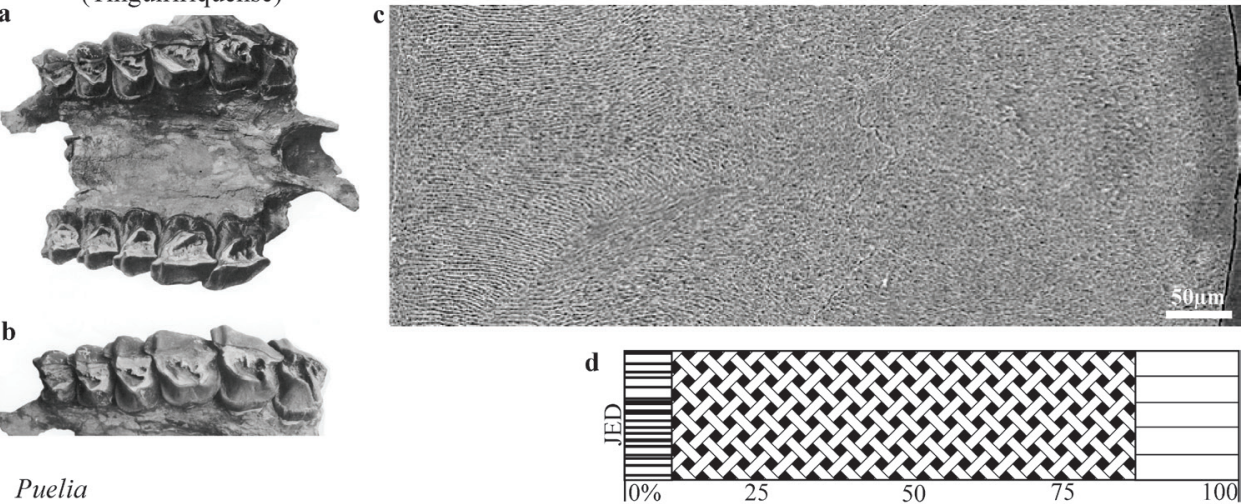

B Puelia

(Tinguiririquense)

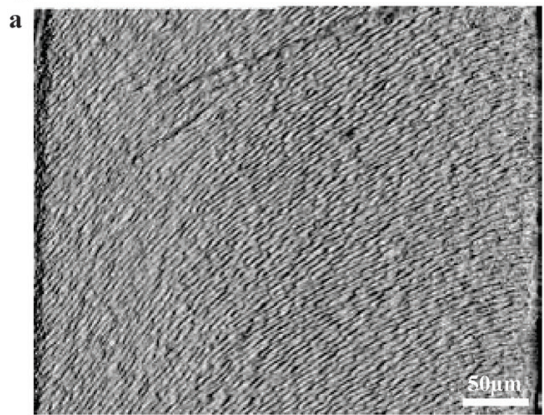

C

Scarrittia

(Deseadense)

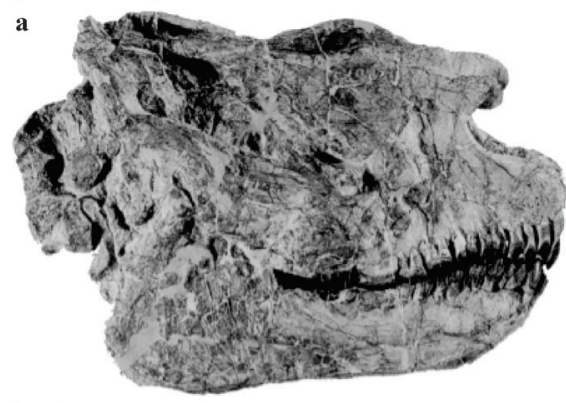

b

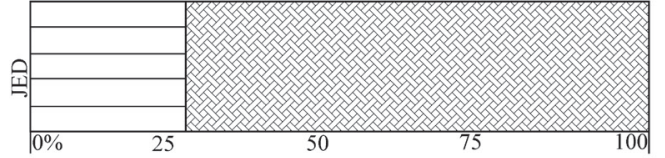

b

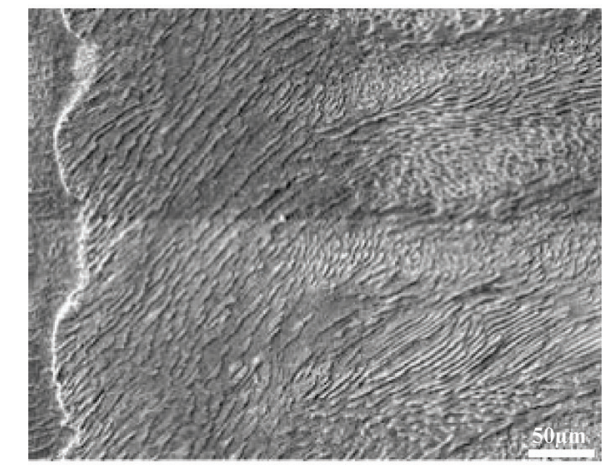

Bandas transversais pouco desenvolvidas

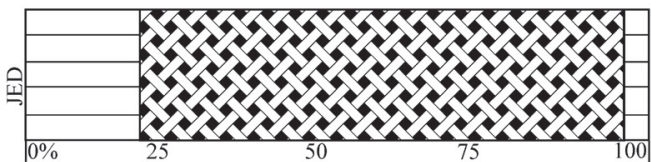

Fig 7 Espécies de Toxodontia (Homalodotheriidae, Notohippidae e Leontiniidae) do Neógeno sul-americano. Eletromicrografias de varredura de secções transversais e longitudinais em molares inferiores de toxodontes ao longo do Cenozoico. Junto às eletromicrografias encontram-se diagramas representando a microestrutura do esmalte, com as zonas deste tecido observadas nestas espécies. A, Periphragnis harmeri (Tinguiririquense); a, vista ventral da porção posterior do crânio com P2-M3 esquerdos; b, detalhe do maxilar esquerdo; c, eletromicrografia de secção transversal do molar inferior; d, diagrama ilustrando a microestrutura do esmalte em molar inferior; B, Puelia (Tinguiririquense); a, eletromicrografia de secção longitudinal do molar inferior; b, diagrama ilustrando a microestrutura do esmalte em molar inferior; C, Scarrittia (Deseadense); a, crânio e mandíbula, vista lateral direita; b, eletromicrografia de secção longitudinal do molar inferior; c, diagrama ilustrando a microestrutura do esmalte em molar inferior. Os diagramas representam a proporção de cada zona do esmalte desde a junção esmalte-dentina (JED) até à porção externa do dente. Modificado de Fortelius (1985) e Lindenau (2005). Fotografias dos espécimes retiradas de Simpson (1967, lâmina 35), Chaffee (1952, lâmina 10) e e eletromicrografias de Lindenau (2005). 
A

Nesodon sp.

(Santacruzense) a
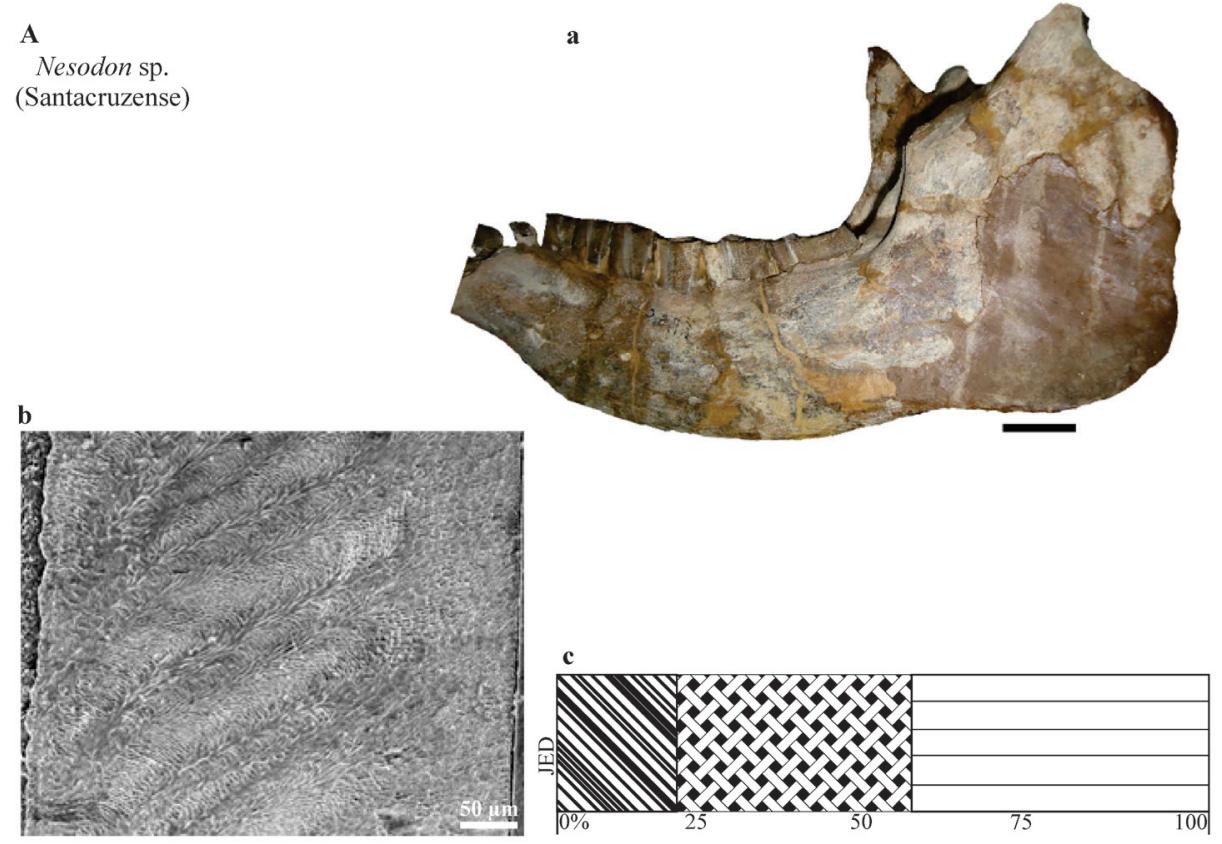

B

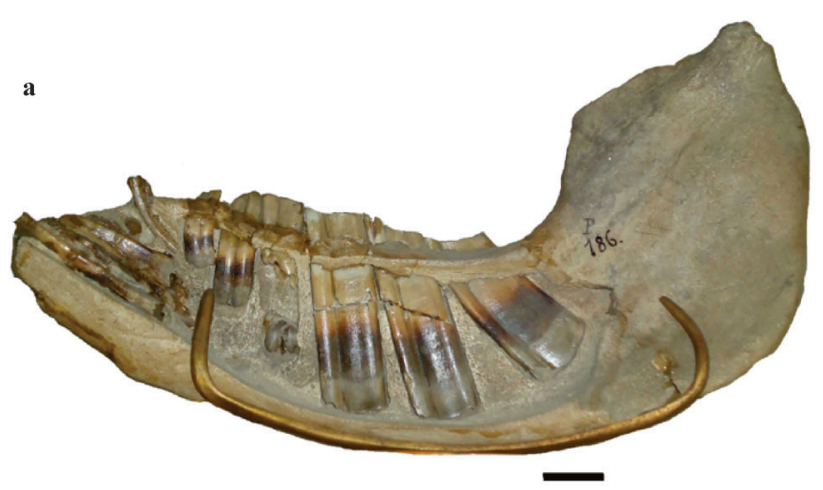

b
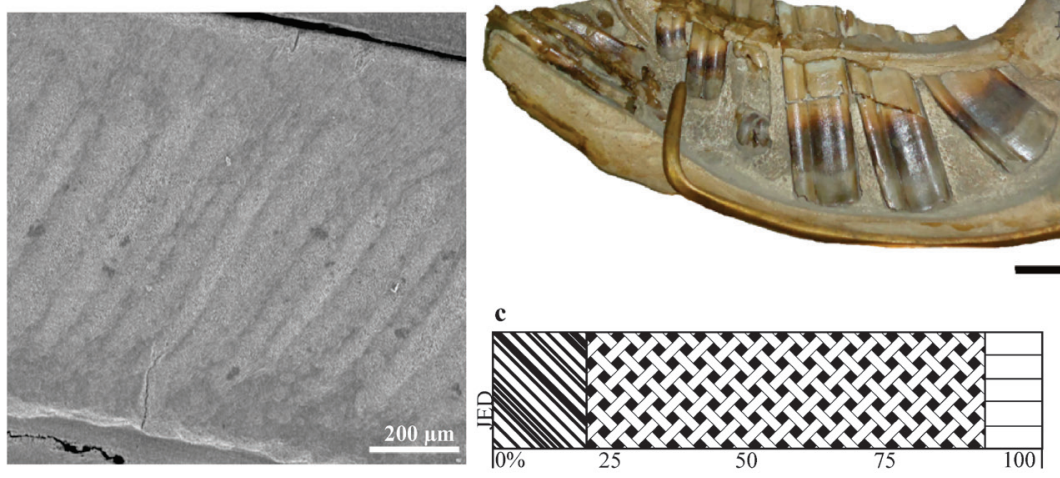

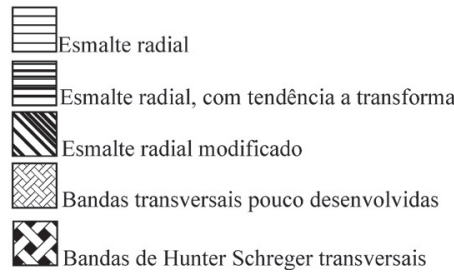

Fig 8 Espécies de Toxodontia (Toxodontidae) do Neógeno sul-americano. Eletromicrografias de varredura de secções longitudinais em incisivos inferiores e superiores de toxodontídeos ao longo do Cenozoico. Junto às eletromicrografias encontram-se diagramas representando a microestrutura do esmalte, com as zonas deste tecido observadas nestas espécies. A, Nesodon (Santacruzense); a, vista lateral esquerda da mandíbula; b, eletromicrografia do segundo incisivo inferior; c, diagrama ilustrando a microestrutura do esmalte do segundo incisivo inferior; B, Toxodon (Lujanense); a, mandíbula em vista lateral esquerda; b, eletromicrografia do primeiro incisivo superior; c, diagrama ilustrando a microestrutura do esmalte do primeiro incisivo superior. Diagramas representando a microestrutura do esmalte, com as zonas de observadas em molares inferiores em espécimes de Toxodontia da família Toxodontidae. Os diagramas representam a proporção de cada zona do esmalte desde a junção esmalte-dentina (JED) até à porção externa do dente. Modificado de Fortelius (1985) e Lindenau (2005). Fotografias por Ana Maria Ribeiro. Eletromicrografias retiradas de Lindenau (2005) e Braunn (2012). 
o estudo microscópico e, ao MCN/FZBRS, pela permissão e facilidades de estudo durante a realização deste trabalho. Aos revisores deste artigo, Lilian Paglarelli Bergqvist e Marcelo Reguero pelas valiosas considerações. Ao CNPq pela concessão da bolsa de doutorado a Patrícia Braunn (processo $\left.n^{\circ} 140736 / 2012-3\right)$ e produtividade a Ana Maria Ribeiro (processo no 312085/2013-3).

\section{Referências}

Ameghino F. 1887. Observaciones generales sobre el órden de mamíferos extinguidos Sud-Americanos llamados toxodontes (Toxodontia) y synópsis de los géneros y especies hasta ahora conocidos. Anal. Mus. La Plata. 6, xxxii 1027 p. (atlas, 98 pls).

Barreda V., Palazzesi L. 2007. Patagonian vegetation turnovers during the Paleogene-early Neogene: origin of arid-adapted floras. Bot. Rev., 73:31-50.

Bergqvist L.P., Ribeiro A.M. 1998. A paleomastofauna das bacias eoterciárias e sua importância na datação das bacias de Itaboraí e Taubaté. Asoc. Pal. Argent. Publ., 5:19-34.

Billet G. 2011. Phylogeny of the Notoungulata (Mammalia) based on cranial and dental characters. J. Syst. Paleontology 9:481-497.

Bonaparte J.F. 1990. New Late Cretaceous mammals from the Los Alamitos Formation, northern $\mathrm{Pa}-$ tagonia. Nat. Geogr. Res., 6:63-93.

Bonaparte J.F., Soria, M.F. 1985. Nota sobre el primer mamífero del Cretácico Argentino, Campaniano-Maastrichtiano (Condylarthra). Ameghiniana, 21:177-183.

Bond M., Cerdeño E., López, G. 1995. Los ungulados nativos de America del Sur. In: Alberdi M.T., Leone G., Tonni E.P. ed. Evolución biológica y climática de la región pampeana durante los últimos cinco millones de años. Un ensayo de correlación con el Mediterráneo occidental. Madrid: Monografias del Museo Nacional de Ciencias Naturales de Madrid (CSIC), 12:259-275.

Bond M., Deschamps C.M. 2010. The Mustersan age at Gran Barranca: a review. In: Madden R.H., Carlini A.A., Vucetich M.G., Kay R.F. eds. 2010. The Paleontology of Grand Barranca: evolution and environmental change through the middle Cenozoic of Patagonia. Cambridge: Cambridge Univ. Press. p. 255-263.

Bond M., Gelfo J.N. 2010. The South American native ungulates of the Urumaco Formation. In: Sánchez-Villagra M.R., Aguillera O.A., Carlini A.A. eds., Urumaco and Venezuelan Paleontology. The fossil record of the northern neotropics. Indiana Univ. Press, p. 256-268.

Bond M., Kramarz A., Mac Phee R., Reguero M. 2011. A new astrapothere (Mammalia, Meridi- ungulata) from La Meseta Formation, Seymour (Marambio) Island, and a reassessment of previous records of Antarctic astrapotheres. Am. Mus. Novit., 3718:1-17.

Bond M., López G., Reguero M.A., Scillato-Yané G.J., Vucetich M.G. 1998. Los Mamíferos de la Formación Fray Bentos (Edad Mamífero Deseadense, Oligoceno Superior?) de las Provincias de Corrientes y Entre Ríos, Argentina. Asoc. Pal. Argent. Publ., 5:41-50.

Bond M., Reguero M., Vizcaino S., Marenssi S. 2006. A new "South American ungulate" (Mammalia: Litopterna) from the Eocene of the Antarctic Peninsula. In: Francis J.E., Pirrie D., Crame J.A. eds. Cretaceous-Tertiary high-latitude palaeoenvironments, James Ross Basin, Antarctica. Geological Society of London, Special Publications, 258:163-176.

Boyde A., Fortelius M. 1986. Development, structure and function of rhinoceros enamel. Zool. J. Linn. Soc., 87:181-214.

Braunn P.R. 2012. Hipoplasia de esmalte em Toxodon Owen, 1837 (Mammalia, Notoungulata) do Pleistoceno do Estado do Rio Grande do Sul, Brasil. Porto Alegre: Inst. de Geoc. UFRGS. 143p. (Dissert. Mestrado).

Braunn P.R., Ribeiro, A., Ferigolo J. 2014. Microstructural defects and enamel hypoplasia in teeth of Toxodon Owen 1837 from the Pleistocene of Southern Brazil. Lethaia, 47:418-431.

Carlson S. J. 1990. Vertebrate dental structures. In: Carte J.G. ed. Skeletal Biomineralization: Patterns, Processes, and Evolutionary Trends.Van Nostrand Reinhold, 1:531-556.

Cartelle C. 1994. Anomalias e desenvolvimento dentário em algumas espécies extintas de mamíferos do Brasil intertropical. Acta Geol. Leop., 17(39/2):573-584.

Case J.A., Goin F.J., Woodburne M.O. 2005. 'South American' marsupials from the Late Cretaceous of North America and the origin of marsupial cohorts. J. Mammal. Evol., 12:461-494.

Chaffee R.G. 1952. The Deseadan vertebrate fauna of the Scarritt Pocket, Patagonia. Bull. Am. Mus. Nat. Hist., 98:509-562.

Cifelli R.L. 1985. South American Ungulate Evolution and Extinction. In: Webb S.D. ed. The Great American Biotic Interchange. New York: Plenum Press. p. 249-266.

Cione A.L., Azpelicueta M.M., Soibelzon L. 2003. The Broken Zig-Zag: Late Cenozoic large mammals and tortoise extinction in South America. Rev. Museo Arg. Cienc. Nat., 5(1):1-19.

Codron D., Brink J.S., Rossouw L., Clauss M., Codron J., Lee-Thorp J.A. 2008. Functional differentiation of African grazing ruminants: an example of specialized adaptations to very small changes in diet. Biol. J. Linn. Soc., 94:755-764. 
Codron D., Lee-Thorp J.A., Sponheimer M., Codron J., De Ruiter D.; Brink J.S. 2007. Significance of diet type and diet quality for ecological diversity of African ungulates. J. Anim. Ecol., 76:526-537.

Croft D., Flynn J.J., Wyss A.R. 2008. The Tinguiririca Fauna of Chile and the early stages of "modernization" of south american mammal faunas. Arq. Mus. Nac., 66(1):191-211.

Croizat L. 1958. Panbiogeography. Vols. I, IIa and IIb. Published by the author.

Damuth J., Janis C.M. 2011. On the relationship between hypsodonty and feeding ecology in ungulate mammals, and its utility in palaeoecology. Biol. Rev., 86:733-758.

Dantas M.A.T., Dutra R, Cherkinsky A., Fortier D.C., Kamino L.H.Y, Cozzuol, M.A., Ribeiro A.S., Vieira F.S. 2013. Paleoecology and radiocarbon dating of the Pleistocene megafauna of the Brazilian Intertropical Region. Quaternary Res., 79(1):61-65.

Dunn R.E., Madden R.H., Kohn, M.J., Schmitz M.D., Strömberg C.A.E., Carlini A.A., Ré G.H., Crowley J.A. 2013. A new chronology for middle Eocene-early Miocene South American Land Mammal Ages. Geo. Soc. Am. Bull., 125(3/4):539555.

Elissamburu A. 2012. Estimación de la masa corporal en géneros del Orden Notoungulata. Estud. Geol., 68(1):91-111.

Eronen J.T., Pulomäki K., Liu L., Lintulaakso K., Damuth J., Janis C., Fortelius M. 2010a. Precipitation and large herbivorous mammals I: estimates from present-day communities. Evol. Ecol. Res., 12:217-233.

Eronen J.T., Pulomäki K., Liu L., Lintulaakso K., Damuth J., Janis C., Fortelius M. 2010b. Precipitation and large herbivorous mammals II: application to fossil data. Evol. Ecol. Res., 12:235-248.

Fanti F. 2012. Cretaceous continental bridges, insularity, and vicariance in the Southern Hemisphere: which route did dinosaurs take? In: Talent J.A. ed. Earth and Life. Global biodiversity, extinction intervals and biogeographic perturbations through time. International Year of Planet Earth. New York: Springer. p. 883-909.

Ferigolo J. 1999. Late Pleistocene South-American land-mammal extinctions: The infection hipothesis. In: Rabassa J., Salemme M. ed. Quaternary of South America and Antarctic Peninsula. Rotterdam: A. A. Balkema, 12:279-310.

Flynn J.J., Wyss A.R., Croft D.A., Charrier R. 2003. The Tinguiririca fauna, Chile: biochronology, paleoecology, biogeography, and a new earliest Oligocene South American Land Mammal 'Age'. Palaeogeogr. Palaeoclimatol. Palaeoecol., 195:229-259.

Fortelius M. 1985. Ungulate cheek teeth: developmental, functional, and evolutional interrelations. Acta Zool. Fenn., 180:1-76.
Fortelius M., Solounias N. 2000. Functional characterization of ungulate molars using the abrasionattrition wear gradient: a new method for reconstructing paleodiets. Am. Mus. Nov., 3301:1-36.

García-López D.A., Deraco V., del Papa C. 2017. Fossil mammals of the Quebrada de los Colorados Formation (late middle Eocene) at the locality of La Poma, Salta Province, Argentina, Hist. Biol., DOI: 10.1080/08912963.2017.1299150.

Gelfo J.N., Goin F.J., Woodburne M.O., Muizon C. 2009. Biochronological relationships of the earliest South American Paleogene mammalian faunas. Paleontology, 52:251-269.

Goin F.J., Pascual R., Tejedor M.F., Gelfo J.N., Woodburne M.O., Case J.A., Reguero M.A., Bond, M., Lopez G.M., Cione A.L., Sauthier D.U., Balarino L., Scasso R.A., Medina F.A., Ubaldon M.C. 2006. The earliest Tertiary therian mammal from South America. J. Vertebr. Paleont., 26(2):505-510.

Goin F.J., Tejedor M.F., Chornogubsky L., Lopez G.M., Gelfo J.N., Bond M., Woodburne M.O., Gurovich Y., Reguero M.A. 2012. Persistence of a Mesozoic, non-therian mammalian lineage (Gondwanatheria) in the mid-Paleogene of Patagonia. Naturwissenschaften, 99:449-463.

Janis C.M. 1988. An estimation of tooth volume and hypsodonty indices in ungulate mammals, and the correlation of these factors with dietary preferences. Mem. Mus. Hist. Nat., 53:367-387.

Janis C.M. 1995. Correlations between craniodental morphology and feeding behaviour in ungulates: reciprocal illumination between living and fossil taxa. In: Thomason J.J. ed. Functional morphology in vertebrate paleontology. Cambridge: Cambridge Univ. Press, p.76-98.

Janis C.M., Ehrhardt D. 1988. Correlation of relative muzzle width and relative incisor width with dietary preference in ungulates. Zool. J. Linn. Soc., 92:267-284.

Janis C.M, Fortelius M. 1988. On the means whereby mammals achieve increased functional durability of their dentitions, with special reference to limiting factors. Biol. Rev., (63):197- 230.

Kaiser T., Müller, D., Fortelius M., Schulz E., Codron D., Clauss M. 2013. Hypsodonty and tooth facet development in relation to diet and habitat in herbivorous ungulates: implications for understanding tooth wear. Mamm. Rev., 43:34-46.

Kay R.F., Madden R.H. 1997a. Paleogeography and Paleoecology. In: Kay R.F., Madden R.H., Cifelli R.L., Flynn J.I. eds. Vertebrate Paleontology in the Neotropics: the Miocene fauna of La Venta, Colombia. Washington: Smithsonian Books. p. 520-550.

Kay R.F., Madden R.H. 1997b. Mammals and rainfall: paleoecology of the middle Miocene at La Venta (Colombia, South America).J. Hum. Evol., 32:161-199. 
Kay R.F., Madden R.H., Vucetich M.G., Carlini A.A., Mazzoni M.M., Re G.H., Heizleri M., Sandeman H. 1999. Revised geochronology of the Casamayoran South American Land Mammal Age: Climatic and biotic implications. P. Natl. Acad. Sci. USA, 96(23):13235-13240.

Koenigswald W.v. 2011. Diversity of hypsodont teeth in mammalian dentitions - construction and classification. Palaeontogr. Abt. A., 294(1-3):63-94.

Koenigswald W.v., Clemens W.A. 1992. Levels of complexity in the microstructure of mammalian enamel and their application in studies of systematics. Scanning Microscopy, 6(1):195-218.

Koenigswald W.v., Rensberger J.M, Pfretzschner H.U. 1987. Changes in the tooth enamel of early Paleocene mammals allowing increased diet diversity. Nature, 328:150-152.

Koenigswald W.v., Sander P.M. 1997. Glossary of terms used for enamel microstructures. In: Koenigswald W.v., Sander P.M. eds. Tooth enamel microstructure. Rotterdam: Balkema, p. 267-280.

Kramarz A.G., Vucetich M.G., Carlini A.A., Ciancio M.R., Abello M.A., Deschamps, C.M., Gelfo, J.N. 2010. A new mammal fauna at the top of the Gran Barranca sequence and its biochronological significance. In: Madden R.H., Carlini A.A., Vucetich M.G., Kay R.F. eds. 2010. The Paleontology of Grand Barranca: evolution and environmental change through the middle Cenozoic of Patagonia. Cambridge: Cambridge Univ. Press. p. 264-277.

Leigh E.G., O'Dea A., Vermeij G.J. 2013. Historical biogeography of the Isthmus of Panama. Biol. Rev., 89(1):148-72.

Lindenau C. 2005. Zahnschmelzmikrostrukturen südamerikanischer Huftiere. Bonn, Germany: Univ. Bonn. 245f. (Tese Dout.).

Lopes R.P., Ribeiro A.M., Dillenburg, S.R., Schultz C.L. 2013. Late middle to late Pleistocene paleoecology and paleoenvironments in the coastal plain of Rio Grande do Sul State, Southern Brazil, from stable isotopes in fossils of Toxodon and Stegomastodon. Palaeogeogr. Palaeodimatol. Palaeoecol., 369:385-394.

López, G.M., Ribeiro A.M., Bond M. 2010. The Notohippidae (Mammalia, Notoungulata) from Gran Barranca: preliminary considerations. In: Madden R.H., Carlini A.A., Vucetich M.G., Kay R.F. eds. 2010. The Paleontology of Grand Barranca: evolution and environmental change through the middle Cenozoic of Patagonia. Cambridge: Cambridge Univ. Press. p. 143-151.

Lundelius J.R.E.L., Bryant V.M., Mandel R., Thies K.J., Thoms A. 2013. The first occurrence of a toxodont (Mammalia, Notoungulata) in the United States. J. Vertebr. Paleont., 33(1):229-232.

Maas M.C. 1997. Enamel microstructure in notoungulates. In: Kay R.F. et al. eds. 1997. Vertebrate
Paleontology in the Neotropics, The Miocene Fauna of La Venta, Colombia. Washington and London: Institution Press. p. 319-334.

Macfadden B.J. 2000. Cenozoic mammalian herbivores from the Americas: reconstructing ancient diets and terrestrial communities. Ann. Rev. Ecol. Syst., 31:33-59.

Macfadden B.J. 2005. Diet and habitat of toxodont megaherbivores (Mammalia, Notoungulata) from the late Quaternary of South and Central America. Quaternary Res., 64:113-124.

Macfadden B.J., Cerling T.E., Prado J. 1996. Cenozoic terrestrial ecosystem evolution in Argentina: evidence from carbon isotopes of fossil mammal teeth. Palaios, 11(4): 319-327.

Mcnaughton S.J., Tarrants, J.L., Mcnaughton M.M., Davies R.H. 1985. Silica as a defense against herbivory and as a growth promoter in African grasses. Ecology, 66:528-535.

Madden, R.H. 2015. Hipsodonty in mammals. Evolution, Geomorphology, and the role of Earth Surface Processes. Cambridge Univ. Press, Cambridge, United Kingdom, 446 pp.

Marshall L.G., Sempere T. 1993. Evolution of the Neotropical Cenozoic land mammal fauna in its geochronologic, stratigraphic, and tectonic context. In: Goldblatt P. ed. Biological Relationships between Africa and South America. New Haven: Yale Univ. Press, p. 329-392.

Marshall L.G., Hoffstetter R., Pascual R. 1983. Mammals and stratigraphy: geochronology of the continental mammal-bearing Tertiary of South America. Paleovertebrata, Mém. Ext., p. 1-93.

Marshall L.G., Webb S.D., Sepkoski, J.J., Raup D.M. 1982. Mammalian evolution and the Great American interchange. Science, 215:1351-1357.

Mendoza M., Janis C.M., Palmquivst P. 2002. Characterizing complex craniodental patterns related to feeding behaviour in ungulates: a multivariate approach. J. Zool. Lond., 258:223-246.

Mendoza M., Palmqvist P. 2008. Hypsodonty in ungulates: an adaptation for grass consumption or for foraging in open habitat? J. Zool., 274:134-142.

Miller K.G., Kominz, M.A., Browning J.V., Wright J.D., Mountain G.S., Katz M.E., Sugarman P.J., Cramer B.S., Christie-Blick N., Pekar S.F. 2005. The Phanerozoic record of global sea-level change. Science, 312:1293-1298.

Mones A. 1982. An equivocal nomenclature: What means hypsodonty? Paleont. Zh., 56(1/2): 107-111.

Ocean Drilling Stratigraphic Network Plate Tectonic Reconstruction Service. URL: <http://www. odsn.de/odsn/services/paleomap/paleomap. html>. Acesso 03.05.2014.

Oliveira É.V., Goin F.J. 2011. A reassessment of bunodont metatherians from the Paleogene of Itaboraí (Brazil): systematics and age of the Itaboraian 
Salma. Rev. Bras. Paleont., 14(2):105-136.

Ortiz-Jaureguizar E., Cladera G.A. 2006. Paleoenvironmental evolution of southern South America during the Cenozoic. J. Arid. Environ., 66:498-532.

Pascual R. 2006. Evolution and geography: the biogeographic history of South American land mammals. Ann. Mo. Bot. Gard., 93:209-230.

Pascual R., Ortiz-Jaureguizar E. 1990. Evolving climates and mammal faunas in Cenozoic South America. J. Hum. Ev., 19:23-60.

Pascual R., Ortiz-Jaureguizar E. 2007. The Gondwanan and South American Episodes: two major and unrelated moments in the history of the south american mammals. J. Mammal. Evol., 14:75-137.

Patterson B., Pascual R. 1972. The fossil mammal fauna of South America. In: Keast A., Erk F.C., Glass B. eds. Evolution, Mammals and Southern Continents. Albany, State Univ. of New York Press. p. 247-309.

Paula Couto, C. 1979. Tratado de Paleomastozoologia. Rio de Janeiro: Academia Brasileira de Ciências, p. 389-417.

Pfretzschner H.U. 1992. Enamel microstructure and hypsodonty in large mammals. In: Smith P., Tchernov E. eds. 1992. Structure, function and evolution of teeth. London/Telaviv: Freund Publishing House, p. 147-162.

Reguero M., Candela A.M., Cassini G.H. 2010. Hypsodonty and body size in rodent-like notoungulates. In: Madden R.H., Carlini A.A., Vucetich M.G., Kay R.F. eds. 2010. The Paleontology of Grand Barranca: evolution and environmental change through the middle Cenozoic of Patagonia. Cambridge: Cambridge Univ. Press. p. 362-371.

Reguero M, Gelfo J.N., López G.M., Bond M., Abello A., Santillana S.N., Marenssi S. 2014. Gondwana breakup: the Paleogene South American native ungulates and the demise of the South America-Antarctica land connection. Glob. Planet. Chang., 123:400-413.

Reguero M., Goin F., Hospitaleche C. A., Dutra T., Marenssi S. 2013. Late Cretaceous/Paleogene West Antarctica Terrestrial Biota and its intercontinental affinities. New York: Springer. 120p.

Reguero M., Prevosti F.J. 2010. Rodent-like notoungulates (Typotheria) from Gran Barranca, Chubut Province, Argentina: phylogeny and systematic. In: Madden R.H., Carlini A.A., Vucetich M.G., Kay R.F. eds. 2010. The Paleontology of Grand Barranca: evolution and environmental change through the middle Cenozoic of Patagonia. Cambridge: Cambridge Univ. Press. p. 152-169.

Rensberger J.M. Koenigswald, W. 1980. Functional and phylogenetic interpretation of enamel microstructure in rhinoceroses. Paleobiology, 6:477-495.

Ribeiro A.M. 2003. Contribuição ao conhecimento da família Leontiniidae (Mammalia, Notoungulata, To- xodontia): aspectos anatômicos e filogenéticos. Porto Alegre: Universidade Federal do Rio Grande do Sul. 213f. (Tese Doutorado).

Ribeiro A.M., Madden R.H., Negri F.R., Kerber L., Hsiou A.S., Rodrigues K.A. 2013. Mamíferos fósiles y biocronología en el suroeste de la Amazonia, Brasil. Asoc. Pal. Argent. Publ., 14:207-221.

Rougier G.W., Chornogubsky L., Casadio S., Arango N.P., Gaillombardo A. 2009a. Mammals from the Allen Formation, Late Cretaceous, Argentina. Cretaceous Res., 30:223-238.

Rougier G.W., Forasiepi A.M., Hill R.V., Novacek M.J. 2009b. New mammalian remains from the Late Cretaceous La Colonia Formation, Patagonia, Argentina. Acta Palaeontol. Pol., 54(2):195-212.

Scher H.D., Martin E.E. 2006. The timing and climatic influence of the opening of Drake passage. Science, 312:428-430.

Sedor F.A., Oliveira É.V., Silva D.D., Fernandes L.A., Cunha R., Ribeiro A.M., Dias E.V. 2017. A new South American Paleogene fauna, Guabirotuba Formation (Curitiba, Paraná State, South of Brazil). J. Mamm. Evol., 24(1):39-55.

Shockey B.J., Flynn J.J. 2007. Morphological diversity in the postcranial skeleton of Casamayoran (?middle to late Eocene) Notoungulata and foot posture in notoungulates. Am. Mus. Novit., 3601:1-26.

Sigé B., Sempere T., Butler R., Marshall L.G., Crochet J.Y. 2004. Age and stratigraphic reassessment of the fossil-bearing Laguna Umayo red mudstone unit, SE Peru, from regional stratigraphy, fossil record, and paleomagnetism. Geobios, 37:771-794.

Simpson, G.G. 1953. The major features of evolution. Columbia Univ. Press, New York, p. 1-434.

Simpson G.G. 1967. The beginning of the age of mammals in South America. Part 2, Systematics: Notoungulata, concluded (Typotheria, Hegetotheria, Toxodonta, Notoungulata incertae sedis), Astrapotheria, Trigonostylopoidea, Pyrotheria, Xenungulata, Mammalia incertae sedis. B. Am. Mus. Nat. Hist., 137:1-259.

Simpson G.G. 1980. Splendid Isolation. A curious history of South American mammals. New Haven: Yale. 266p.

Solounias N., Moelleken S.M.C. 1993. Dietary adaptation of some extinct ruminants determined by premaxillary shape.J. Mammal., 74:1059-1071.

Stebbins G.L. 1981. Coevolution of grasses and herbivores. Ann. Mo. Bot. Gard., 68:75-86.

Strömberg C.A.E. 2006. Evolution of hypsodonty in equids: testing a hypothesis of adaptation. Paleobiology, 32(2):236-258.

Strömberg C.A.E., Dunn R.E., Madden R.H., Kohn M.J., Carlini A.A. 2013. Decoupling the spread of grasslands from the evolution of grazer-type herbivores in South America. Nat. Commun., 4(1478):1-8. 
Tejedor M.F., Goin F.J., Gelfo J.N., López G., Bond, M., Carlini A.A., Scillato-Yané G.J., Woodburne M.O., Chornogubsky L., Aragón E., Reguero M.A., Czaplewski N.J., Vincon S., Martin G.M., Ciancio M.R. 2009. New early Eocene mammalian fauna from western Patagonia, Argentina. Am. Mus. Novit., (3638):1-43.

Townsend K.E.B., Croft D.A. 2008. Diets of Notoungulates from the Santa Cruz Formation, Argentina: New Evidence from enamel microwear. J. Vertebr. Paleont., 28(1):217-230.

Ubilla M., Perea D., Bond M. 1994. The deseadan land mammals age in Uruguay and the report of Scarritia robusta nov. sp. (Leontiniidae, Notoungulata) in the Fray Bentos Formation (Oligocene-?Lower Miocene). Geobios, 27(1):95-102.

Van Frank R. 1957. A fossil collection from northern Venezuela 1. Toxodontidae (Mammalia, Notoungulata). Am. Mus. Novit., 18: 1-38.

Van Valen V. 1960. A functional index of hypsodonty. Evolution, 14:531-532.

Webb S.D. 2006. The Great American Biotic Interchange: patterns and processes. Ann. Mo. Bot. Gard., 93:245-257.
Webb S.D., Perrigo S.C. 1984. Late Cenozoic Vertebrates from Honduras and El Salvador. J. Vertebr. Paleont., 4(2):237-254.

Wilf P., Cúneo N.R., Escapa I.H., Pol D., Woodburne M.O. 2013. Splendid and seldom isolated: The paleobiogeography of Patagonia. Annu. Rev. Earth Pl. Sc., 41:561-603.

Williams S.H., Kay R.F. 2001. A comparative test for adaptive explanations for hypsodonty in ungulates and rodents. J. Mamm. Evol., 8:207-229.

Woodburne M.O., Goin F.J., Bond M., Carlini A.A., Gelfo J.N., López G.M., Iglesias A., Zimicz A.N. 2014. Paleogene land mammal faunas of South America; a response to global climatic changes and indigenous floral diversity. J. Mammal. Evol., 21:1-73.

Zachos J.C. McCarren H., Murphy B., Röhl U., Westerhold T. 2010. Tempo and scale of late Paleocene and early Eocene carbon isotope cycles: implications for the origin of hyperthermals. Earth Planet. Sc. Lett., 299:242-249.

Zachos J.C., Dickens G.R., Zeebe R.E. 2008. An early Cenozoic perspective on greenhouse warming and carbon-cycle dynamics. Nature, 451:279-283.

Resumo: Os notoungulados são ungulados nativos sul-americanos registrados do Paleoceno ao Pleistoceno, e cuja diversidade declinou drasticamente durante o Plioceno, alcançando a América Central e América do Norte durante o Pleistoceno. Notoungulados evoluíram sob influência climática e ambiental, de linhagens arcaicas, com sistema mastigatório generalizado, com dentição completa, sem diastema, com molares e pré-molares braquiodontes, a formas especializadas com incisivos hipertrofiados, padrões oclusais da coroa simplificados e formas proto-hipsodontes e eu-hipsodontes. Estas comunidades viveram primeiramente em hábitats florestais quentes e úmidos, e posteriormente, em pastagens relativamente temperadas de hábitats abertos, com forte tendência à aridização e ao resfriamento ao longo do Cenozoico. Além da evolução da morfologia macroscópica dentária observada em Notoungulata, também é possível evidenciar a evolução dos tipos de microestrutura do esmalte, por meio da presença de características mais derivadas em formas eu-hipsodontes, indicando adaptação funcional e conferindo maior resistência ao consumo de vegetação mais abrasiva.

Palavras-Chave: Cenozoico, Mudanças paleoambientais, Mudanças paleoclimáticas, Notoungulata, Paleohistologia dentária. 